Research Article

\title{
Mechanical Response of Gasketed Bell-and-Spigot Joint of Concrete Pipeline under Multifield Coupling
}

\author{
Hang He $\mathbb{D}^{1,2,3}$ Hongyuan Fang $\mathbb{D}^{1,2,3}$ Xueming Du $\mathbb{D}^{1,2,3}$ and Bin $\operatorname{Li} \mathbb{C}^{1,2,3}$ \\ ${ }^{1}$ College of Water Conservancy Engineering, Zhengzhou University, Zhengzhou 450001, China \\ ${ }^{2}$ National Local Joint Engineering Laboratory of Major Infrastructure Testing and Rehabilitation Technology, \\ Zhengzhou 450001, China \\ ${ }^{3}$ Collaborative Innovation Center of Water Conservancy and Transportation Infrastructure Safety, Zhengzhou 450001, \\ Henan Province, China
}

Correspondence should be addressed to Hongyuan Fang; 18337192244@163.com and Xueming Du; dxm2019@zzu.edu.cn

Received 18 November 2019; Revised 8 May 2020; Accepted 23 May 2020; Published 15 June 2020

Academic Editor: Giuseppe Oliveto

Copyright (c) 2020 Hang He et al. This is an open access article distributed under the Creative Commons Attribution License, which permits unrestricted use, distribution, and reproduction in any medium, provided the original work is properly cited.

Concrete pipe may suffer joint failure under the coupling effect of internal fluid and overlying load, which may lead to pipe leakage. Based on Abaqus and Fluent finite element software, a three-dimensional refined model of drainage pipeline with gasketed bell-andspigot joints and flow field model inside the pipeline was established. Fully considering the compression of the gasket during pipeline assembly and pipe-soil interaction, the fluid-structure coupling numerical simulation was carried out by using the MpCCI (Meshbased parallel Code Coupling Interface) platform, and the mechanical response of the concrete pipe joint under the multifield loads coupling effects of burial condition, traffic load, and internal fluid was studied. The accuracy of the coupling model was verified through the full-scale tests that have been carried out. The influences of various factors on the circumferential stress and vertical deformation of the joint were mainly studied. The result reveals that the influence of different working conditions on the circumferential stress of the pipe joint is mainly concentrated on the crown and the invert of the joint, the areas vulnerable to tensile damage. The change of flow field leads to a slight difference in the vertical deformation of the joint, while variation in gasket hardness and cushion compactness has a certain influence on the vertical deformation of the joint. The change of buried depth has a negative correlation to the vertical deformation of the joint, and the change of load position has a significant nonlinear effect. The result provides a theoretical basis for further research on the mechanical mechanism of the pipeline joints during operation.

\section{Introduction}

As an important part of the urban infrastructure, the concrete pipeline with gasketed bell-and-spigot joints is the "underground lifeline" to ensure the normal operation of the city's function. However, during the long-term operation, due to the complicated environment of pipeline burial and the coupling influences of overlying loads (traffic and soil pressure), fluid loads and the pipe-circumference environment, the damage may occur to the joint of the pipe segment with asymmetric structure, resulting in problems such as the pipeline explosion and even leading to safety accidents such as the road collapse, which will have a negative impact on social economy. Besides, the domestic and foreign researches (Romer and Kienow [1], Elachachi et al. [2]) found that most accidents of the pipeline damage are caused by the failure of gasketed bell-and-spigot joints. Therefore, in order to reveal the mechanics of the concrete pipeline with gasketed bell-and-spigot joints during operation and apply it to the structural design and maintenance of the pipeline to better exert its performance, it is necessary to study the stress and deformation characteristics of the gasket bell-and-spigot joints of the concrete pipeline under the multiload coupling.

Benmansour et al. [3] carried out an analysis of the drainage pipelines in the Greater Lyon region of France with the CCTV technology. It found that the main cause of pipeline failure was related to its longitudinal response, and the pipeline defect occurred mostly at the joints. Taking other assumptions into account, Scarino [4] believed the pipeline joint to be a hinge capable of transmitting shear stress, and he solved the 
differential settlement problem by numerical methods. Rakitin and $\mathrm{Xu}$ [5] conducted a series of centrifuge tests on buried largediameter reinforced concrete pipelines with gaskets and belland-spigot joints and compared the influence of the burial depth of the soil layer as well as the location and magnitude of the traffic load to the stress of the pipeline. Xu et al. [6] also used the three-dimensional numerical simulation method to study the longitudinal response of $1400 \mathrm{~mm}$ large-diameter reinforced concrete buried pipeline with gasket and bell-and-spigot joints under the traffic load and compared the longitudinal responses of the pipelines under different buried depths, soil stiffness, gasket modulus, and positions of the load. Through comparison with the laboratory results, the longitudinal deformation of the pipe joint is analyzed. Romer and Kienow [1] hold that although there are many studies on the design and manufacture of concrete pipes, the joints that are rarely studied are the main cause of pipeline accidents. So they introduced new models or examples of concrete pipes with gaskets and discussed the latest technology of concrete pipe joints with gasket and proposed the joint design applications under different working conditions. Becerril García and Moore [7] studied the response of the belland-spigot joints of concrete pipes, which were subjected to maximum working load and explained the influence of the pipe diameter, the burial depth, the load position, and the backfill quality on the joint performance by measuring the response of the pipeline segments. Besides, the response of the same pipe to maximum loads at shallow depths was also investigated. Buco et al. [8] developed a device for testing the performance of pipe joints under various load conditions. A simple rheological bilinear model of the pipe joint was established from test results and verified by the test results. Wang et al. [9] studied the dynamic response of the drainage pipe under pulse loading through establishing a three-dimensional model of concrete pipe with bell-and-spigot joints through Abaqus and taking the influence of pipe-soil interaction and gasket on the bell-andspigot joints into consideration. The mechanical response of the pipeline under different working conditions such as the magnitude and the position of the load, as well as the depth of the pipeline, is compared to analyze the mechanical properties of the bell-and-spigot joints. Li et al. [10] studied the dynamic response of concrete pipeline under traffic load and groundwater by carrying out the full-scale tests and multifield coupling simulation, and the influence of various factors on the dynamic response of the pipeline was analyzed. Zhai et al. [11] proposed externally bonded CFRP repair technology to solve the broken wire problem of PCCP pipeline. Therefore, a refined model of PCCP pipeline was established, and the influences of various factors on the mechanical properties of the pipeline after repair were analyzed and studied.

In addition to the overlying soil pressure and the traffic load, the external load acting on the pipeline also includes the fluidstructure interaction (FSI) between the fluid in the pipeline and the pipeline, which has a negligible significance for the structural stress analysis and research of the pipeline network system. Laithier and Païdoussis [12] describe and derive general formulas for fluid transport piping dynamics, including flow changes, Coriolis forces, centrifugal forces, and moments of inertia, using appropriate statements of Hamilton's principles. Wiggert and Tijsseling [13] classified FSI technologies and summarized their generation mechanisms. Li et al. [14] studied the mechanical response of buried corroded concrete drainage pipes under multifield coupling by fluid-solid coupling numerical simulation. The results reveal the influence of various factors on the dynamic response of corroded concrete pipes, and a full-scale test was conducted to verify the accuracy of the model. Xu et al. [15] used the ANSYS Workbench platform for numerical simulation of fluid-structure coupling, studied the heat transfer and medium flow characteristics of L-shaped heat pipelines, and analyzed and compared the pressure and temperature of the flow field and the elbow structure of the pipeline under different working conditions. Zhang and Li [16] carried out fluid-structure coupling and fluid-structure-heat coupling numerical simulation of the tee pipe joint by MpCCI and analyzed the Mises stress and displacement of the three-way pipe. Li et al. [17] established a three-dimensional refined model of buried concrete pipeline, analyzed and studied the dynamic response of the pipeline under the coupling effect of traffic load and groundwater level fluctuations, and carried out relevant field tests. Li et al. [18] have also studied the mechanical properties of concrete drainage pipeline under multiphysical coupling conditions including overburden pressure, traffic loads, groundwater, and pipe fluids through fluid-structure coupling numerical methods and pointed out the most significant factors.

At present, none of the existing researches on pipeline joints have refined modeling, especially where the compression of the gasket during pipeline assembly is ignored, the load considered is relatively single in analyzing the mechanical characteristics of the joint, in which the influence of fluid inside the pipeline is also ignored. So the purpose of this paper is to establish a pipeline refined model with bell-and-spigot joints and fluid model inside pipeline on the previous studies and to carry out multifield fluidstructure coupling through the MpCCI platform under considering the compression of the gasket during pipeline assembly, so as to study the mechanical response characteristics of concrete pipeline joints under the coupling of traffic and operating loads, and verify the accuracy of the fluid-structure coupling simulation with the data of the full-scale test. Besides, this paper is also aimed to analyze the effects of traffic load, burial conditions, gasket performance, and fluid force on the mechanical response and vertical deformation of the concrete pipe joint, by which the action rules of various influencing factors are obtained, so as to provide a theoretical basis for studying the mechanics of the concrete pipeline joints.

\section{Three-Dimensional Numerical Simulation Model}

2.1. Model of the Pipeline. A three-dimensional soil model and a concrete pipeline refinement model were established in Abaqus 6.14-1, as shown in Figure 1. The soil model was divided into two layers: pavement and foundation. The thickness of the pavement layer was $0.2 \mathrm{~m}$ and the thickness of the foundation was $6.8 \mathrm{~m}$. The pavement adopted the linear elastic constitutive model. The foundation adopted the Mohr Coulomb's elastoplastic constitutive model, and a sand-gravel cushion was laid under the pipeline, which was set according to 06MS201 «Municipal Drainage Pipeline Process and Ancillary Facilities》 [19], as shown in Figure 2. The pipeline consisted of six 


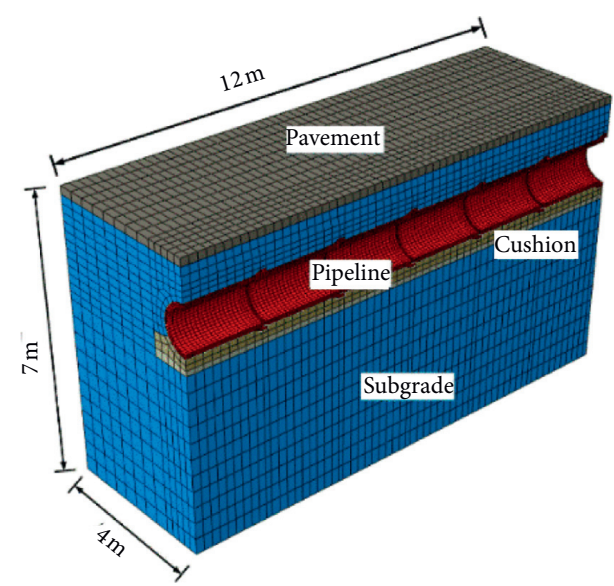

Figure 1: 3D refined model mesh geometry.

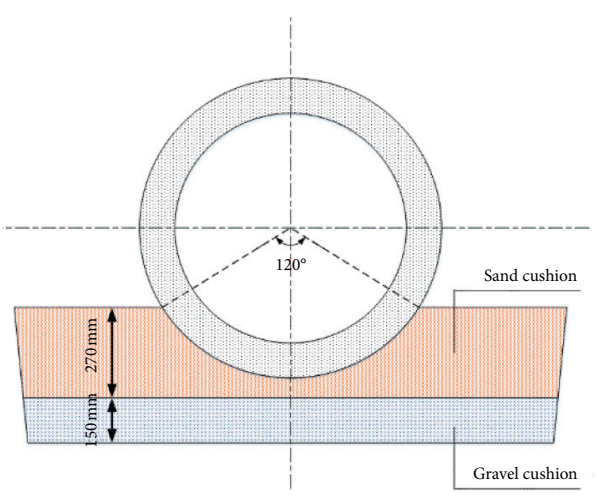

FIGURE 2: Simulation of pipeline cushion.

sections of $1000 \mathrm{~mm}$ diameter pipes with gasketed bell-andspigot joints, which was described by the C30 concrete damage plasticity model proposed by Lee and Fenves [20]. The detailed material parameters are shown in Table 1 .

The gasket is used as the sealing material for the pipe joint in this paper. Becerril García [7] and Xu et al. [6] simplified the gasket of the pipe into a linear elastic material to analyze the behavior of the pipe joint. However, according to the research of Zhang [21] and Liu et al. [22], the gasket has obvious nonlinear elastic behavior. Therefore, the gasket was simplified into a circular hyperelastic material in this numerical simulation, the gasket adopted the Mooney-Rivlin function, which is widely used in engineering, and its strain energy function equation is as follows:

$$
U=C_{10}\left(I_{1}-3\right)+C_{01}\left(I_{2}-3\right)+\frac{1}{D_{1}}(J-1)^{2},
$$

where $U$ is the strain energy, $I_{1}$ and $I_{2}$ are the invariants of the deformation tensor of the rubber material, $J$ is the compression coefficient of the rubber material, $C_{10}$ and $C_{01}$ are material parameters of the Mooney-Rivlin model, and $D_{1}$ is a constant parameter. Referring to the relevant literature, the specific parameters of the gasket material are shown in Table 2. And in consideration of the possible slippage between the gasket and the joint surface, the contact unit was arranged on the inner wall of the gasket and the outer wall of the spigot, as well as the outer wall of the gasket and the inner wall of the bell.
The tangential direction of the contact unit used the "penalty" function and the coefficient of friction is 0.2 , while "hard" contact was used in the normal direction.

In order to ensure the accuracy and efficiency of the calculation model, the pipeline and soil model files created in Abaqus were imported into Hypermesh 13.0 software for meshing by using hexahedral structure grid, and the soil grids near the concrete pipeline and the bell-and-spigot joint were encrypted. The concrete pipeline and the soil were meshed by eight-node hexahedral elements (C3D8R), and the gasket adopted the eight-node hexahedral hybrid elements (C3D8RH). The hourglass control of all grids was enhanced. The maximum size and minimum size of the soil grid are $0.4 \mathrm{~m}$ and $0.1 \mathrm{~m}$, respectively, while the maximum size of the pipeline grid is $0.1 \mathrm{~m}$. After the model was divided, there are 76152 units and 92435 nodes.

2.1.1. Traffic Load Model. The falling weight deflectometer (FWD) is a widely used detection method in the field of highway inspection. Its principle is to lift and drop a heavy hammer through the hydraulic system controlled by the computer, so as to create a pulse load to the road surface [23]. Because FWD does a better job in simulating the actual traffic load, so the traffic load of this simulation adopted the pulse load of the FWD instrument, and the measured curve is shown in Figure 3. As shown in Figure 4, the traffic load acted above the central pipe joint, its amplitude was set to $700 \mathrm{kPa}$ according to the magnitude of the vehicle load, and the effective area was $0.4 \mathrm{~m} \times 0.2 \mathrm{~m}$ according to the contact area between the wheel and the pavement. The boundary conditions of the structure field were as follows: the freedom of displacement in three directions on the bottom of the model and the freedom of normal displacement in four sides of the model were constrained.

2.1.2. Assembly of the Pipeline. This paper simulated the assembly process of the concrete pipes considering the compression of the gasket by the life-and-death element method, of which the principle is to multiply the stiffness matrix of the selected element by a small factor when the load of the selected element will be zero so that the load vector is not effective (but it still appears in the list of element loads). When the selected element is reactivated, its stiffness, mass, element load, and other values will be restored, but the reactivated element has no strain record.

The specific implementation method of the assembly of the simulation pipeline was as follows: first, under the "interaction module" in Aabqus, using "Model change" to select all the soil elements except the pipeline and the gasket and set them to "kill" in the first analysis step, and compressed the gasket installed on the spigot to the inner surface of the bell along the axial direction, and fixed the vertical displacement of each spigot; in the second step, the soil elements "killed" in the first step were "activated" in this analysis step, and the external surface of the completed compressed gasket was placed in contact with the inner surface of the bell, as shown in Figure 5. The surrounding soil then began to apply load to the pipeline while lifting the vertical fixation at the pipe spigot. At this time, the assembly of the concrete pipeline with gasket was completed. 
TABLE 1: Property of materials in numerical analysis.

\begin{tabular}{|c|c|c|c|c|c|}
\hline Property & Elastic modulus (MPa) & Poisson's ratio & Density $\left(\mathrm{kg} / \mathrm{m}^{3}\right)$ & Cohesion $(\mathrm{kPa})$ & Dilation $\left(^{\circ}\right)$ \\
\hline Pavement layer & 2400 & 0.3 & 2400 & & \\
\hline Subgrade & 20 & 0.3 & 2000 & 25 & 0.1 \\
\hline Sand cushion & 47.24 & 0.3 & 1870 & 0.001 & 20 \\
\hline Gravel cushion & 120 & 0.28 & 2200 & & \\
\hline Concrete pipes & 30 & 0.2 & 2300 & & \\
\hline
\end{tabular}

TABle 2: Parameters of gasket.

\begin{tabular}{lccc}
\hline Hardness & $\mathrm{C}_{01}(\mathrm{MPa})$ & $\mathrm{C}_{10}(\mathrm{MPa})$ & $\mathrm{D}_{1}\left(\mathrm{MPa}^{-1}\right)$ \\
\hline THA42 & 0.23196 & 0.08811 & $5.67 \mathrm{E}-02$ \\
THA55 & 0.47591 & 0.11248 & $3.45 \mathrm{E}-02$ \\
THA72 & 0.64479 & 0.32135 & $1.32 \mathrm{E}-02$ \\
\hline
\end{tabular}

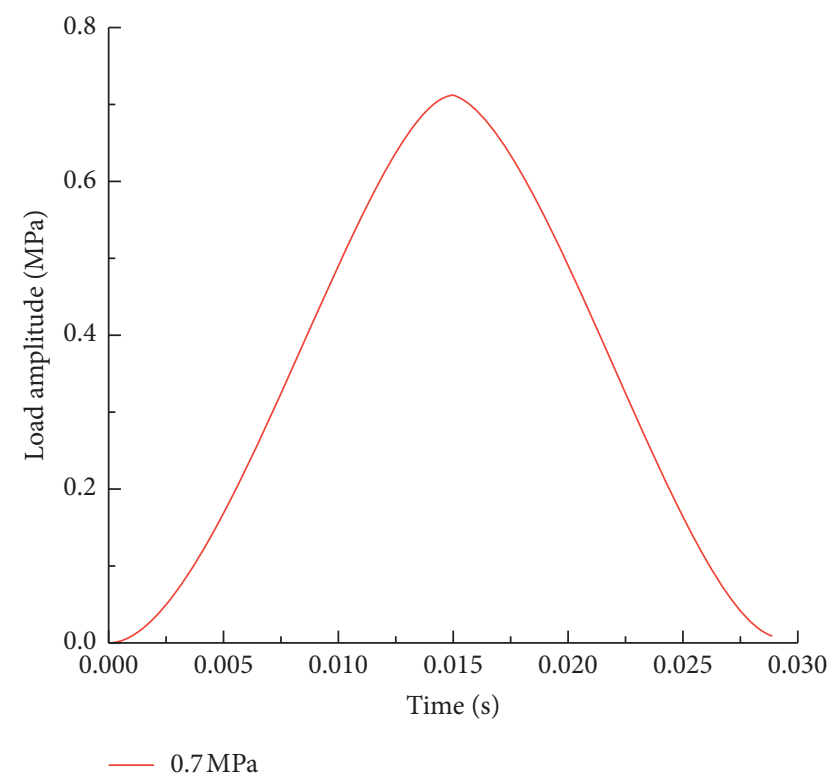

Figure 3: The amplitude of impulse load.

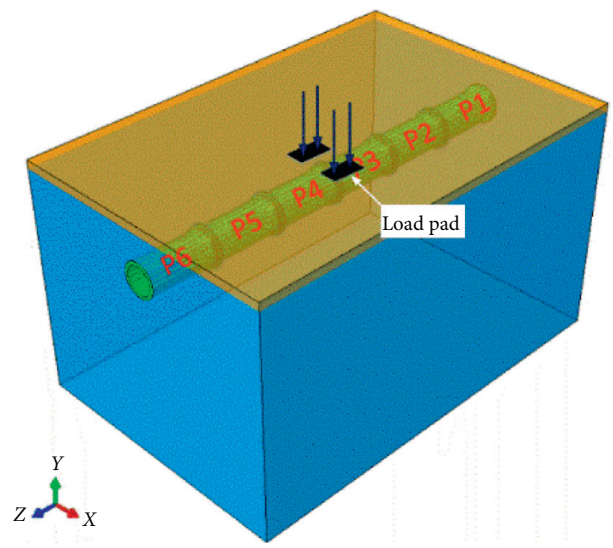

Figure 4: The location of the traffic load.

\subsection{Details of the Fluid Model}

2.2.1. Flow Field Model. In this paper, a three-dimensional flow field model was established in Fluent in the condition of

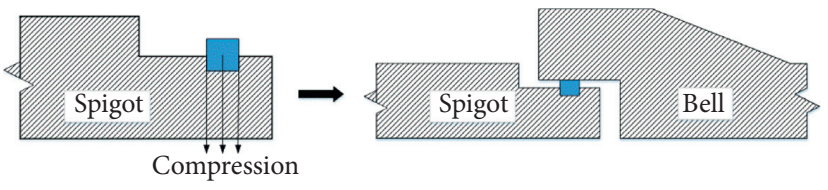

Figure 5: Assembly of the gasketed bell-and-spigot joint.

the normal operation of the concrete drainage pipeline. The calculation domain was the internal cylindrical area of the concrete drainage pipeline, with a diameter of $1.0 \mathrm{~m}$ and a total length of $11.9 \mathrm{~m}$, and there were gas-liquid two phases in the flow field. The flow field geometry was established by ANSYS Workbench Design Model. It is worth noting that the three-dimensional coordinates of the flow field need to correspond to the structural field. Then the created flow field model was imported into ICEM CFD (a preprocessing software in ANSYS) for meshing. According to the simulation, the geometric shape of the flow field model was relatively regular, so the calculation domain of the flow field adopted the structured grid with higher calculation accuracy. Firstly, the geometric model of the flow field was imported into ICEM CFD. Then the flow field model was meshed by the hexahedral structured grid through using the "O-Block" grid division technology. In order to better carry out the fluid-structure coupling numerical simulation, the size of the flow field grid is basically consistent with that of the pipeline grid, and the flow field grid is shown in Figure 6.

2.2.2. Calculation Model. The internal flow of the simulated drainage pipe is complicated, so it is important to select the appropriate turbulence model and multiphase flow model in Fluent. Zhang et al. [24] found that RNG k- $\varepsilon$ model has the advantages of high accuracy and good numerical stability in the simulation of turbulent flow in a nonpressure circular pipe, so RNG k- $\varepsilon$ model was used to deal with the turbulent flow inside the pipeline, and its transport equation is as follows:

$$
\begin{aligned}
\frac{\partial(\rho k)}{\partial t}+\frac{\partial\left(\rho k u_{i}\right)}{\partial x_{i}}= & \frac{\partial}{\partial x_{j}}\left[\propto_{k} \mu_{e f f} \frac{\partial k}{\partial x_{j}}\right]+G_{k}+\rho \varepsilon, \\
\frac{\partial(\rho \varepsilon)}{\partial t}+\frac{\partial\left(\rho \varepsilon u_{i}\right)}{\partial x_{i}}= & \frac{\partial}{\partial x_{j}}\left[\propto_{\varepsilon} \mu_{e f f} \frac{\partial \varepsilon}{\partial x_{j}}\right] \\
& +\left(C_{1 \varepsilon}-\frac{\eta\left(1-\left(\eta / \eta_{0}\right)\right)}{1+\beta \eta^{3}}\right) \frac{\varepsilon}{k} G_{k}-C_{2 \varepsilon} \rho \frac{\varepsilon^{2}}{k} .
\end{aligned}
$$




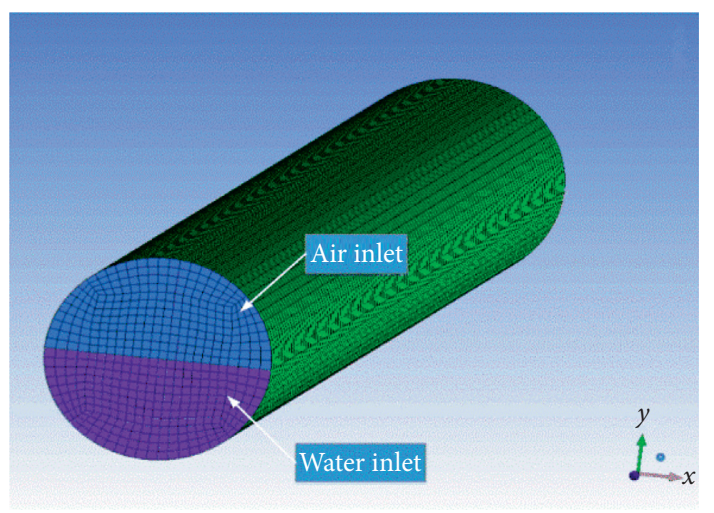

FIgURE 6: Diagram of flow field mesh.

Among them, $\rho$ represents the constant density; $k$ represents the turbulent kinetic energy; $\propto_{k}$ and $\propto_{\varepsilon}$ are the turbulent Prandtl numbers; $\mu_{\text {eff }}$ is the effective viscosity; $\varepsilon$ is the turbulent dissipation rate; $C_{1 \varepsilon}, C_{2 \varepsilon}, \eta_{0}$ and $\beta$ are the default constants in Fluent; $\eta=\left(2 E_{i j} \cdot E_{i j}\right)^{0.5}(k / \varepsilon)$, $E_{i j}=(1 / 2)\left[\left(\partial u_{i} / \partial x_{j}\right)+\left(\partial u_{j} / \partial x_{i}\right)\right], G_{k}$ represents the turbulent kinetic energy due to the average velocity gradient; $G_{b}$ represents the turbulent kinetic energy due to the buoyancy; $Y_{M}$ represents the contribution of the wave expansion in the compressible turbulence to the total dissipation rate; $u_{i}$ represents the velocity of the fluid in the $x_{i}$ direction;

Choosing the VOF model which is suitable for multiphase flow with a free interface between water and air. A fluid model was used to solve the flow problem of two-phase or multiphase flow [25]; that is, each phase obeys the same set of momentum conservation equations:

$$
\frac{\partial(\rho \bar{V})}{\partial t}+\nabla \cdot(\rho \overline{V V})=-\nabla p+\nabla \cdot\left[\mu\left(\Delta \bar{V}+\Delta \overline{V^{T}}\right)\right]+\rho \bar{g} .
$$

In the formula, $\rho$ is the density of each phase, $\bar{V}$ is the velocity vector of the fluid, $p$ is the pressure, $\mu$ is the viscosity coefficient, and $\bar{g}$ is the acceleration of gravity.

2.2.3. Boundary Condition. Flow field boundary conditions include the following aspects:

(1) Inlet: it was divided into a water inlet and air inlet due to the actual operation of the drainage pipeline. According to the relevant standard [26], the flow velocity and flow of the water inlet were specified, the air inlet was set as a pressure inlet suitable for inlet pressure known but flow velocity unknown, and the value of the pressure was set to the value of the atmospheric pressure.

(2) Outlet: it was composed of air and water, but the flow condition of each phase at the outlet was unknown, so the pressure outlet was adopted, the reference pressure value of the outlet was set as atmospheric pressure value, and the position of the reference point was set above the geometric center of the pressure outlet.
(3) Wall: no sliding wall condition was adopted because the selected RNG k- $\varepsilon$ model was a turbulence model suitable for the high Reynolds coefficient, so the standard function wall method was used to simulate the flow near the wall of the pipeline. The equation is as follows [14]:

$$
U^{*}=y^{*}, \quad U^{*}=\frac{1}{k} \operatorname{In}\left(E y^{*}\right), \quad y^{*}<11.2, \quad y^{*}>11.2 .
$$

Among them, $\quad U^{*}=\left(U_{p} C_{\mu}^{1 / 4} k_{p}^{1 / 2} /\left(\tau_{w} / \rho\right)\right)$, $y^{*}=\left(y_{p} \rho C_{\mu}^{1 / 4} k_{p}^{1 / 2} / \mu\right), k=0.42, E=8.955$, where $U_{p}$ is the average flow velocity at point $p, k_{P}$ is the turbulent energy at point $p ; y_{P}$ is the distance from point $p$ to the wall, and $\mu$ is the viscosity coefficient.

2.3. Fluid-Structure Coupling Process of the Joint Model under Multifield Loads. MpCCI is a professional coupling interface software for multidisciplinary and multiphysical fields. It has no computing power, but only controls the coupling process, allowing data such as force and displacement to be exchanged between the grids of two simulation codes in multiple physics. Since the grid of structure and flow field are divided by different computing software, the grids at the coupling area are usually not matched. In order to achieve multiphysics coupling, the steps of the data exchange adopted by MpCCI include the following aspects:

(1) Precontact search: classify the same type of mesh for the next step before searching for the corresponding mesh contact of the flow field and the structure

(2) Correlation: for each node or cell of each grid of the coupling region, the grid cells of the corresponding region must be found; then, the data will be exchanged at the relevant cell or node. This process is also known as "neighborhood search"

(3) Interpolation: exchange data to be transferred between already associated units or nodes, as shown in Figure 7

The steps of MpCCI for fluid-structure coupling numerical simulation are shown in Figure 8, it mainly includes the following steps:

Step 1: prepare the model files. Complete the creation of the structural and flow field models in ABAQUS and Fluent, respectively.

Step 2: define the coupling process. Start MpCCI software, import and scan the calculation files of structure field and flow field in sequence, and then select the coupling area and define the physical quantity (RelWalForce and NPosition) to be exchanged. Finally, select the data transmission method of fluid-structure coupling and define the analysis step and step time size of fluid-structure coupling. 


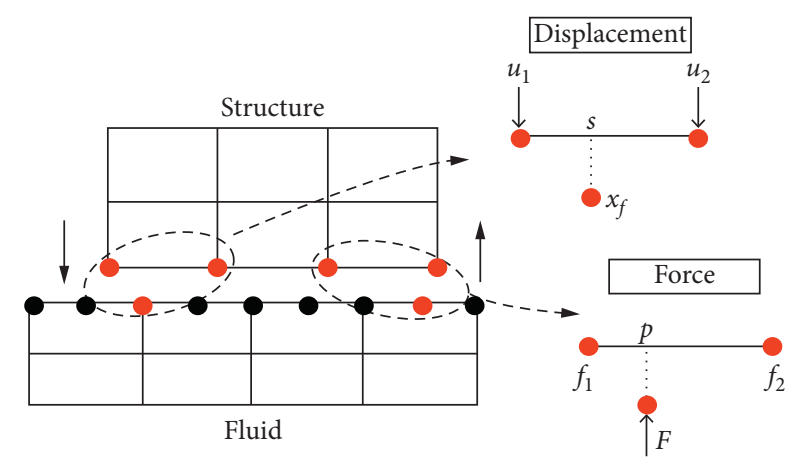

FIgURE 7: Interpolation of MpCCI.

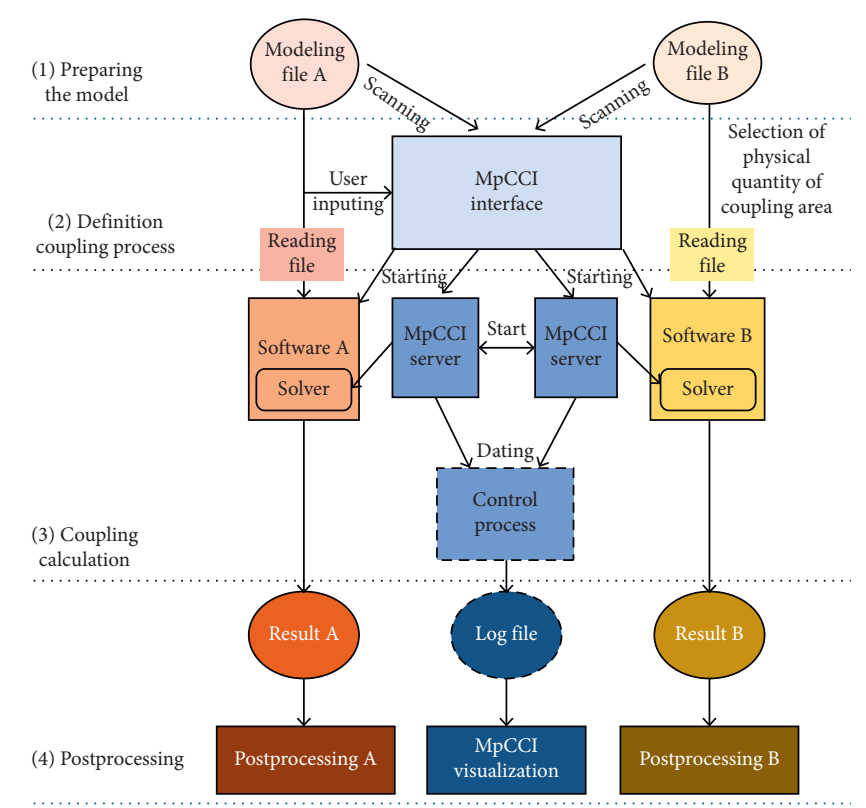

Figure 8: The calculation process of MpCCI.

Step 3: couple the calculation. Before running the fluidstructure coupling calculation, MpCCI calls ABAQUS to carry out the separate calculation before the coupling analysis step, and then uses serial coupling algorithm for calculation with Fluent, as shown in Figure 9; this iteration step can be summarized as follows: (1) calculate the fluid loads and transfer it to the pipeline joints through the interface (between the pipeline and the flow field), (2) calculate the structural field, (3) transfer the displacement of the pipeline joints to the flow field through the interface and update the position of the fluid grid accordingly, and (4) carry out the following iterative calculation. The entire calculation process can be viewed by MpCCI's monitor.

Step 4 (postprocessing): the relevant data are extracted from the Visualization module of ABAQUS.

\section{Discussion of Numerical Results}

Based on the numerical simulation of the fluid-structure coupling under multifield loads, the influence of flow

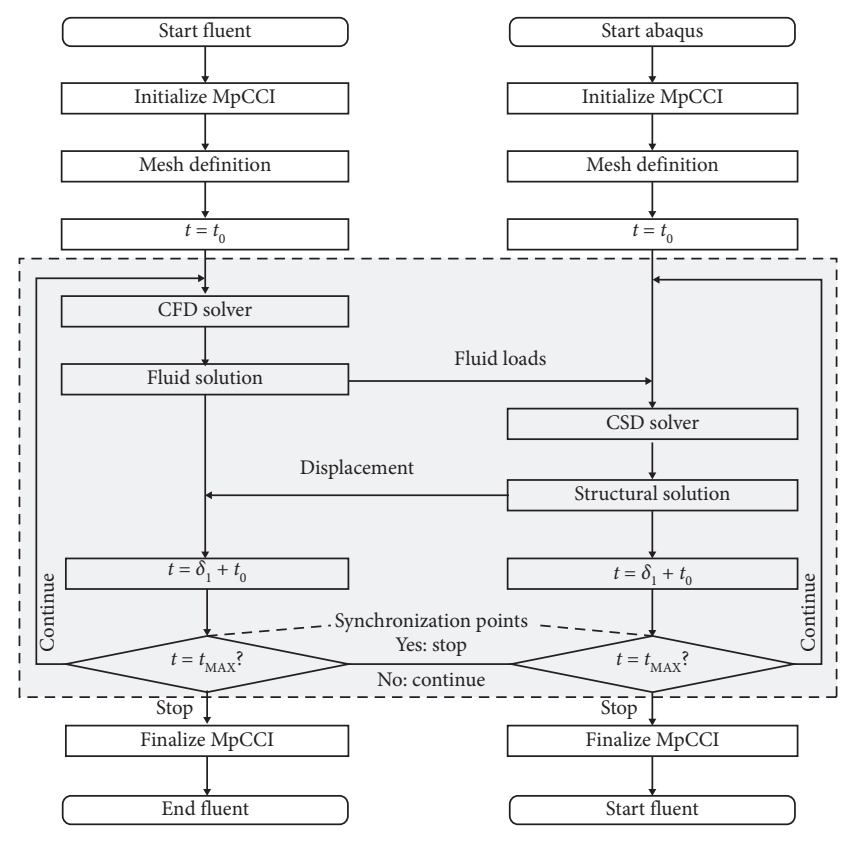

Figure 9: The fluid-structure coupling scheme.

velocity, flow, gasket hardness, cushion compactness, buried depth, and load position on the mechanical response of belland-spigot joint was analyzed by using the control variable method. The distribution of circumferential maximum principal stress and vertical deformation (rotation angle and shear displacement) of bell-and-spigot joints under different working conditions were mainly compared. The rotation and shear displacement of the joint were defined in this paper, as shown in Figure 10, where $\theta$ is defined as the angle of the pipe segment rotating around the joint, and $\delta$ is defined as the vertical distance between the adjacent bell end and spigot end.

3.1. Influence of Flow Velocity. In this section, the effects of flow velocity changes are studied. The flow velocity values were set to $1 \mathrm{~m} / \mathrm{s}, 2 \mathrm{~m} / \mathrm{s}$, and $3 \mathrm{~m} / \mathrm{s}$ according to GB500142006 《Code for the design of outdoor wastewater engineering》 [26]. Under the fluid-structure coupling, the maximum principal stress distribution of the J3 bell is shown in Figure 11. There were obvious peaks and troughs, and the peak position was at the crown and invert of the joint, which was the tension area, while the stress value of the shoulder and the haunch area were relatively small and under pressure. The distribution of the maximum circumferential principal stress of the J3 spigot was similar to that of the bell. It can be seen from the comparison of the two figures that the maximum principal stress value of the bell was significantly larger than that of the spigot. This is because the convex shape of the bell protrudes to bear more load force than the spigot. At this time, the crown and invert of the bell were the most susceptible area to tensile damage. However, the change of flow velocity had no effect on the circumferential stress of the J3 joint almost, only had a weak positive correlation at the top $\left(0^{\circ}\right)$ and bottom $\left(180^{\circ}\right)$ of the joint, and the influence of the spigot was more obvious. It is 


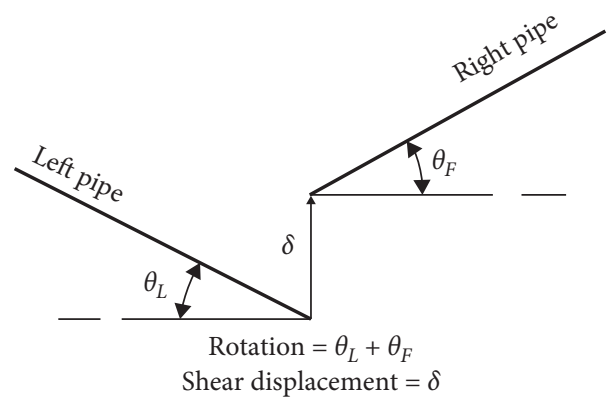

Figure 10: Definition of joint rotation and shear displacement.

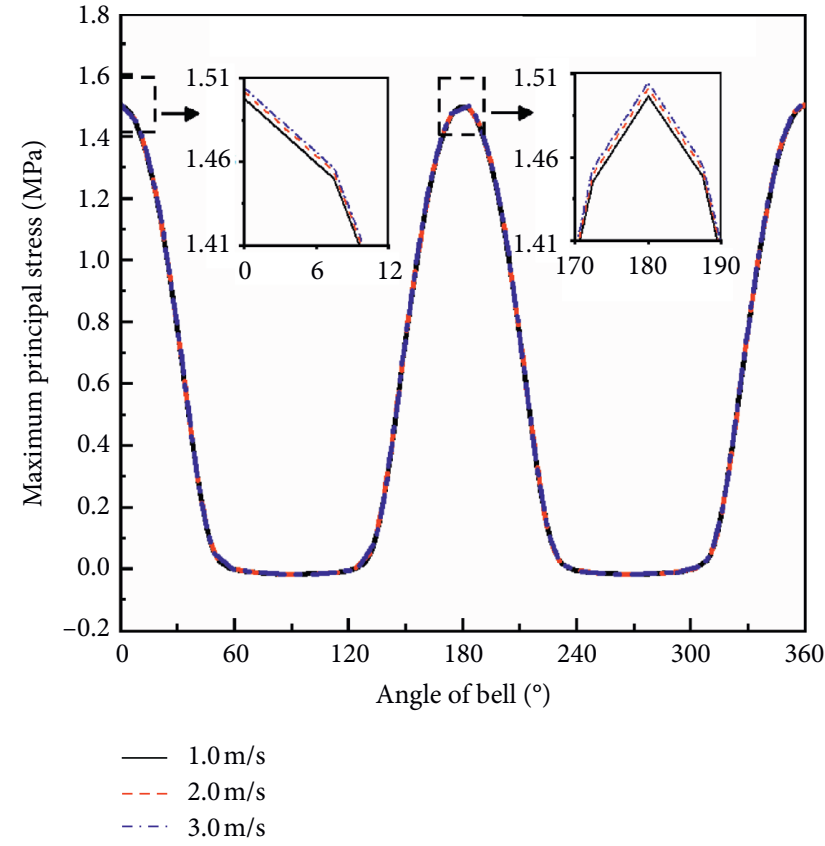

(a)

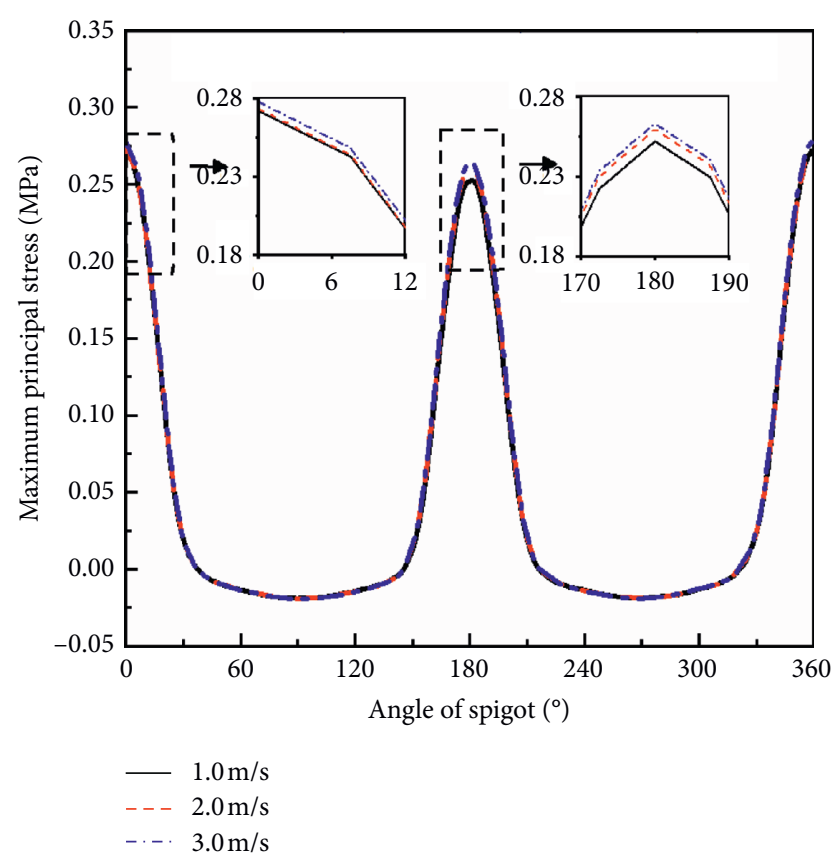

(b)

Figure 11: Maximum principal stress of (a) the bell and (b) the spigot under different flow velocities.

speculated that the spigot is in direct contact with the fluid, while the bell is on the outside of the spigot, so the spigot is more affected by the fluid force.

Figure 12 shows the vertical displacement of the crown of the pipeline under different velocities. The displacement curve was basically symmetrically distributed in the center, but it was not continuous at the pipe joint due to the asymmetric shape. It was worth noting that the vertical displacement at the inlet and outlet is significantly different under the action of the fluid. It can be seen that the change of the flow velocity had a certain positive correlation effect on the vertical displacement of the pipeline, and the range of the effect covers the whole pipeline. However, this effect was decreasing with the flow of fluid in the pipeline.

Since the rotation and shear displacement were highly concentrated at the pipe joint, in order to better study the vertical deformation of the pipe joint under the action of different velocities, the rotation and shear displacements of the J2, J3, and J4 pipe joints are summarized as shown in Figure 13. It can be found that the maximum rotation occurred at the J3 joint, which was caused by the traffic load acting above the central pipe joint. The rotation of J2 and $\mathrm{J} 4$ were obviously smaller than that of $\mathrm{J} 3$, and the rotation of the J4 pipe joint was the smallest, and the influence of velocity change on the rotation of each pipe joint was negligible. The maximum shear displacement appeared at the J4 pipe joint, while the J3 pipe joint had the smallest shear displacement. With the increase of flow velocity, it can be found that the shear displacement of the $\mathrm{J} 3$ and J4 pipe joint increased weakly, while that of the J2 pipe joint decreased weakly, but the distribution rule was not affected.

3.2. Influence of Flow. The effect of flow on the mechanical response of the joint was studied. In addition to the standard 


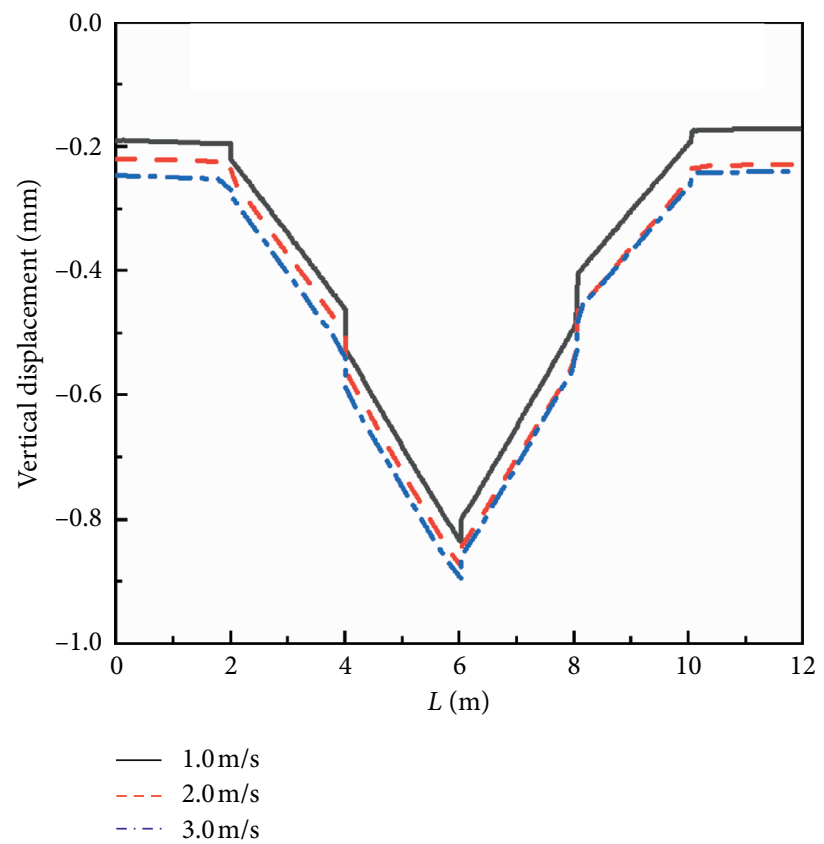

FIgURE 12: Longitudinal vertical displacement of the crown under different flow velocities.

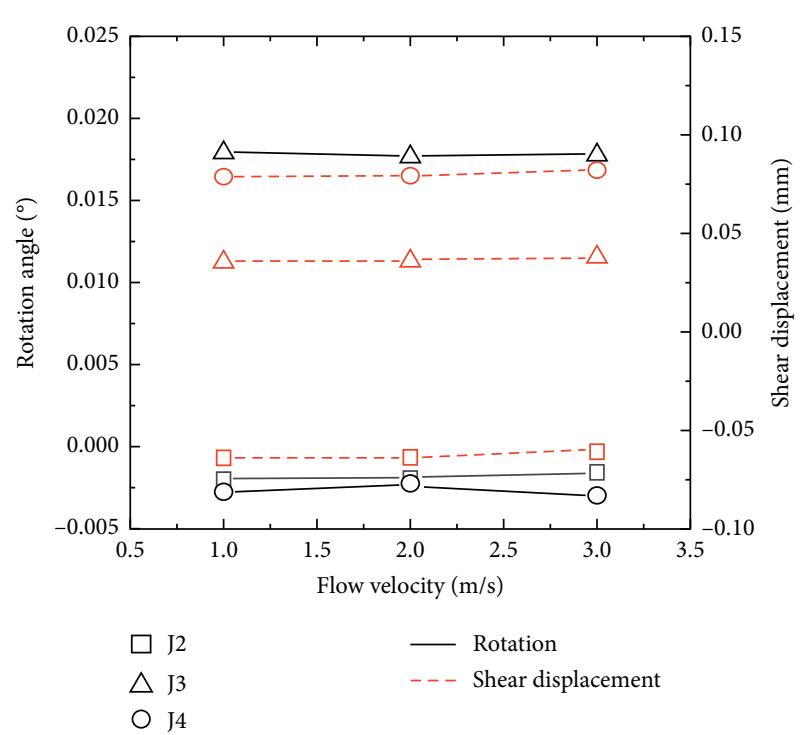

FIGURE 13: Influence of flow velocity on joint rotation and shear displacement.

flow 0.5 , both 0.3 and 0.7 flow were included. Figures 14(a) and 14 (b) show the circumferential maximum principal stress distribution of the J3 bell-and-spigot joint under different flow. The distribution rule was the same as the above. The crown and invert of the joint were tensile and easily damaged areas, while the shoulder and haunch of the joint were compressed and the stress value was small. With the increase of flow, the maximum principal stress distribution and peak-valley value of the bell and spigot was almost not affected, while the maximum principal stress at the crown and invert of the joint slightly increased, and the spigot was more affected than the bell, which was almost the same with the influence rule of flow velocity. It can be found that the flow force had a weak influence on the bell and spigot, but it was worth noticing that the effect of flow was more obvious than that of flow velocity.

The vertical displacement distribution of the pipe crown under different flow is shown in Figure 15, which was still the center symmetrical distribution-high in the middle and low on both sides. As the flow gather, the vertical displacement of the crown increased significantly along the whole pipeline. Similarly, the rotation and the shear displacement of J2, J3, and J4 joints are summarized and shown in Figure 16. It can be seen that the rotation of each joint had little change with the increase of flow. It was presumed that the increase of flow led to the uniform increase of vertical displacement of the pipeline, which can be found in Figure 15. With the increase of flow, the shear displacement of each joint was also slightly affected, which also showed that the difference in vertical deformation of the joint caused by the change of flow was very limited.

3.3. Influence of Gasket Hardness. The gasket is used as flexible support at the joint of the drainage pipe, which was usually treated as linear elastic material in the previous research, such as Xu et al. [6]. In this section, the hyperelastic function was used to realize the simulation of the gasket, and the influence of the three gasket hardness (namely, Tha42, Tha55, and Tha72) on the pipe joint was studied. It can be seen from Figures 17(a) and 17(b) that the change of the gasket hardness did not affect the distribution rule of the circumferential maximum principal stress of the joint and had little effect on the peak value of the maximum principal stress, only slightly different in the positions of the crown and the invert of the bell and the spigot, which were also the most dangerous positions. With the increase of hardness, the smaller the maximum principal stress at the invert was, but the difference was still small compared with the maximum 


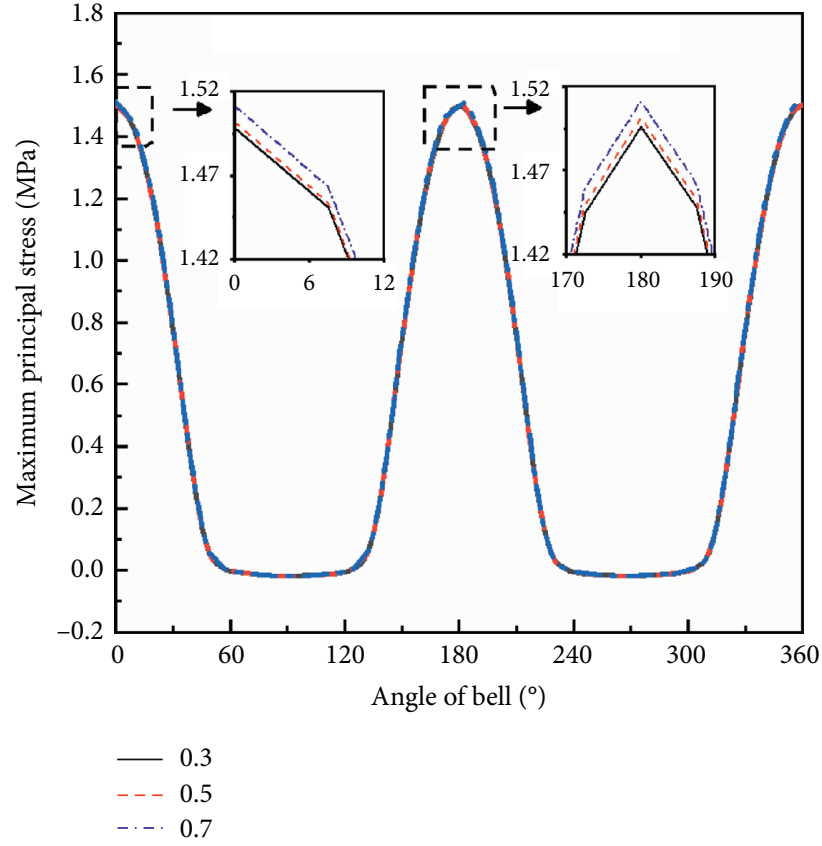

(a)

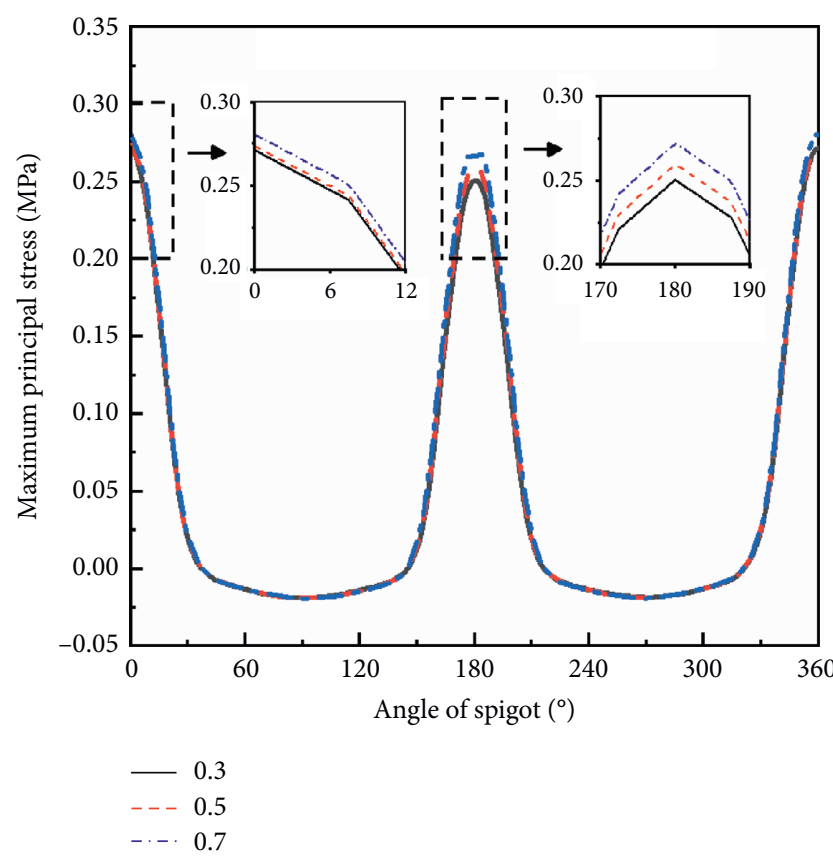

(b)

FIgURE 14: Maximum principal stress of (a) the bell and (b) the spigot under different flow.

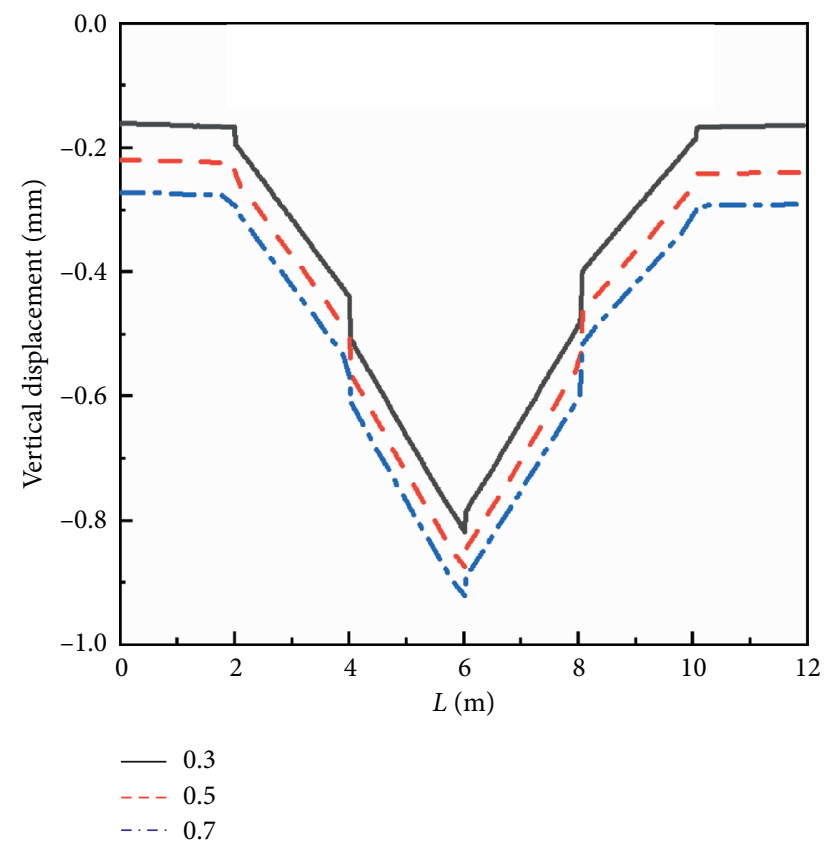

Figure 15: Longitudinal vertical displacement of the crown.

principal stress at the joint, which was also proved in the research of Xu et al. [6] and Becerril García and Moore [7].

Figure 18 shows the vertical displacement of the pipeline under different gasket hardness. It can be found that the vertical displacement decreased to a certain extent with the increase of gasket hardness. The distribution of rotation and shear displacement of the J2, J3, and J4 joints are shown in

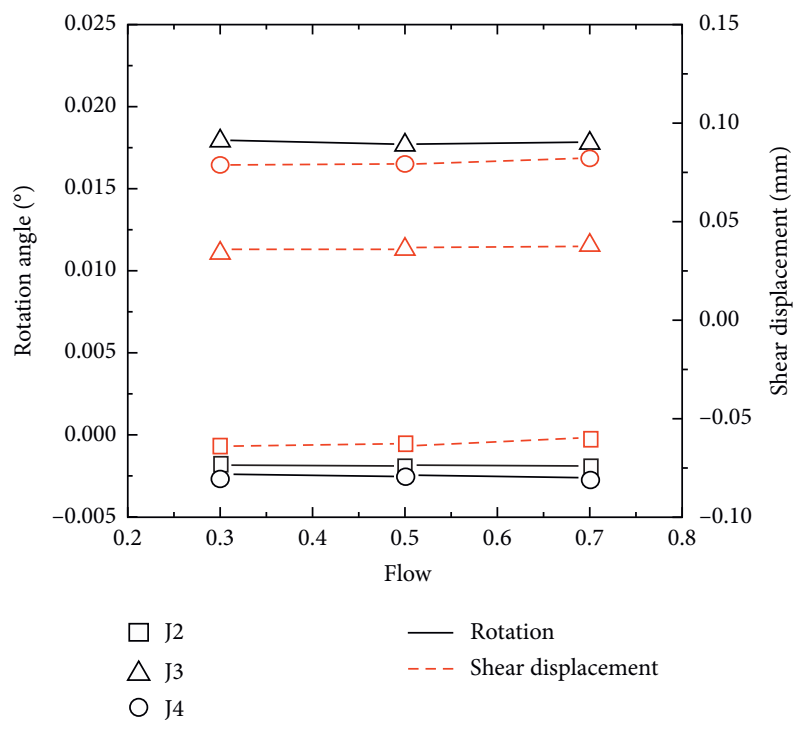

FIGURE 16: Influence of flow on joint rotation and under different flow shear displacement.

Figure 19. It can be seen that the rotation of the J3 joint has certainly increased with the improvement of the hardness of the gasket, but the influence rule of the $\mathrm{J} 2$ joint rotation was just the opposite, and the rotation of the J4 joint was not affected basically. Figure 19 shows that the shear displacement of each joint decreased significantly as the increase of the hardness of the gasket, which indicated that the compression of the gasket between the bell and the spigot decreased due to the increase of the hardness. From the results, it is clear that the change of the gasket hardness had little 


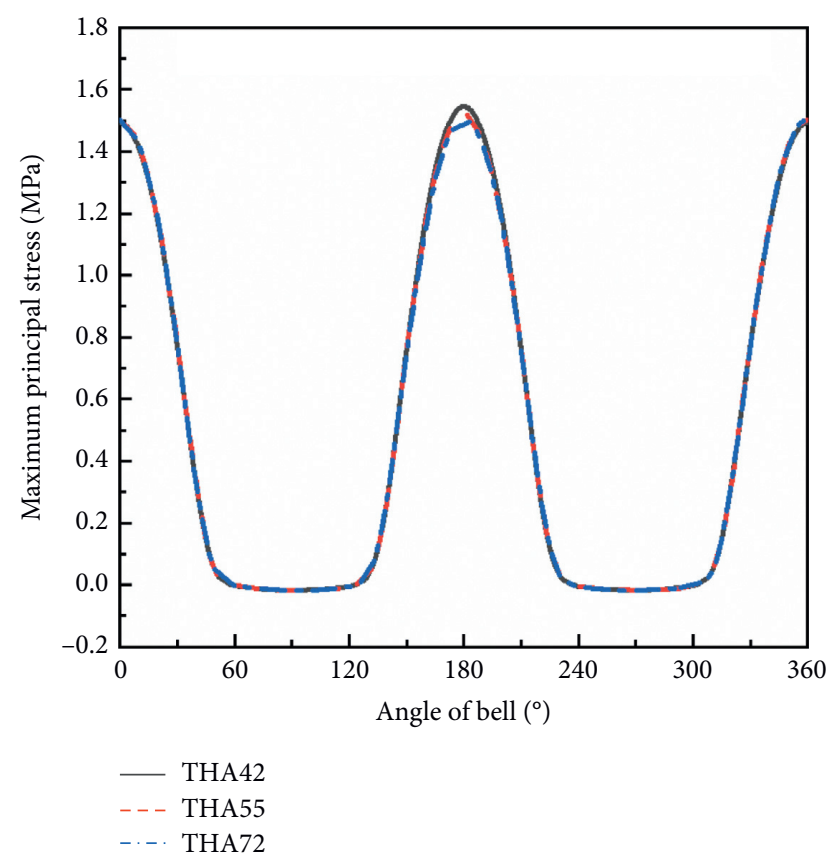

(a)

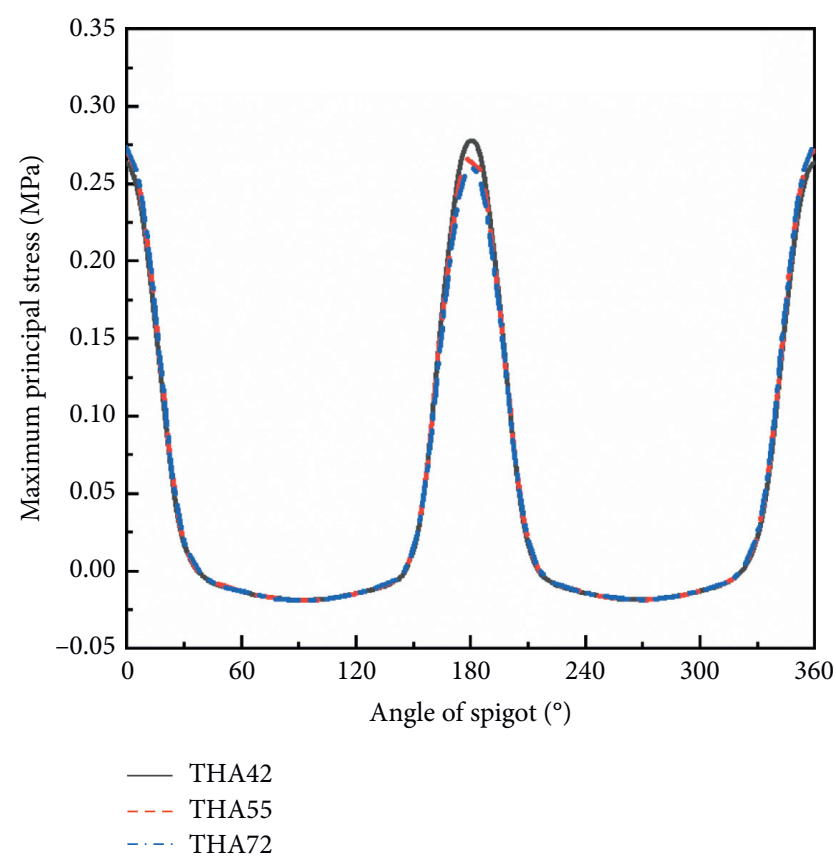

(b)

Figure 17: Maximum principal stress of (a) the bell and (b) the spigot under different gasket hardness.

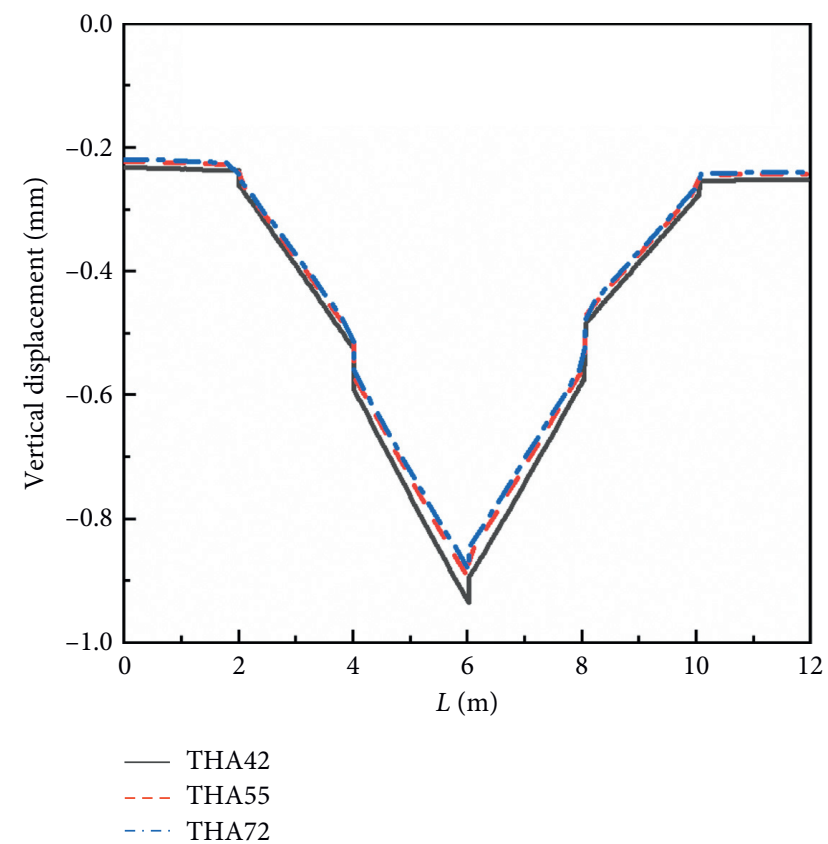

Figure 18: Longitudinal vertical displacement of the crown.

effect on the mechanical properties of the bell and spigot but had a significant effect on the vertical deformation of the joint, especially the shear displacement.

3.4. Influence of Cushion Compaction Degree. The concrete drainage pipe is laid on the cushion. Because of the special shape of the bell, it is easier to contact the pipe cushion than the spigot. Therefore, the compaction degree of the cushion

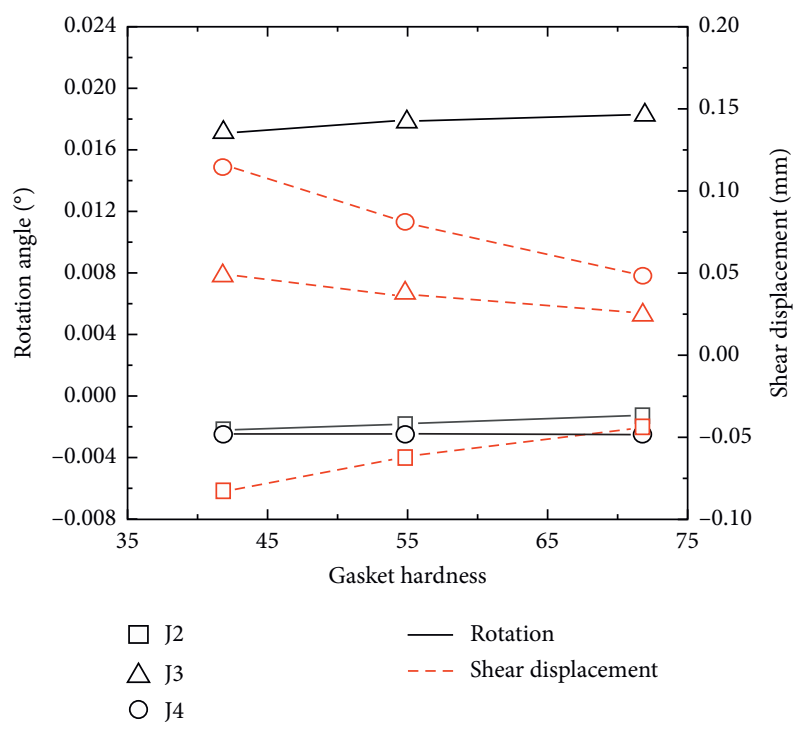

FIGURE 19: Influence of gasket hardness on joint under different gasket hardness rotation and shear displacement.

is important for the analysis of the mechanical behavior of the joint. In this section, according to 06MS201 Municipal Drainage Pipeline Process and Ancillary Facilities [24], the pipeline cushion layer was set as a sand-gravel cushion layer, which was divided into the sand cushion layer and the gravel layer, and the compaction degree of sand cushion layer was $85 \%, 90 \%$, and $95 \%$, respectively. It can be seen from Figures 20(a) and 20(b) that the change of the compaction degree had little influence on the distribution rule of the circumferential maximum principal stress of the pipe joint, but the maximum principal stress of the invert of the bell and 


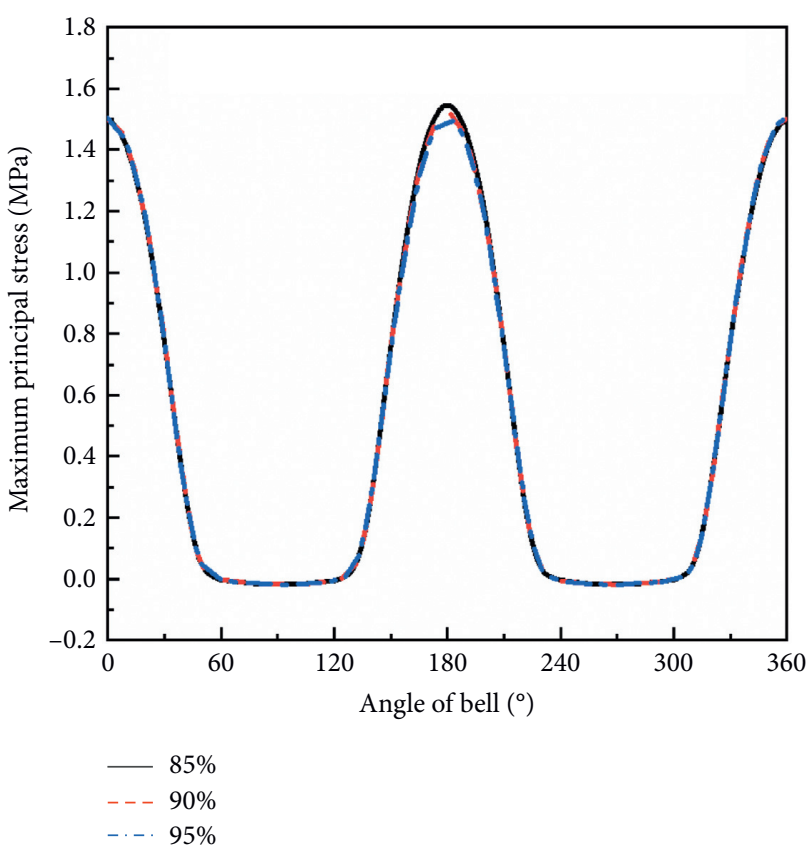

(a)

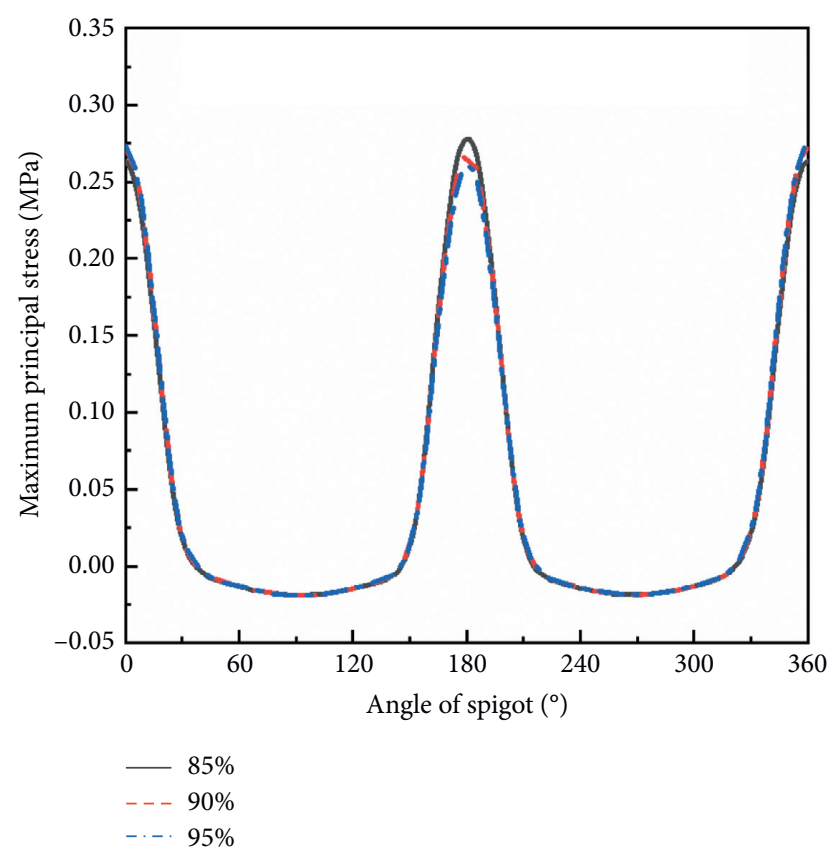

(b)

Figure 20: Maximum principal stress of (a) the bell and (b) the spigot under different compaction degrees.

the spigot slightly increased with the decrease of the compaction degree, which may be caused by the larger contact area between invert and the cushion layer than other parts of the joint.

Figure 21 shows the vertical displacement of the joint crown under the action of different compaction degrees, from which it can be seen that the change of compaction degree had an impact on the vertical behavior of the joint. This was because the improvement of buried conditions had a better supporting performance for the pipe. The summary of rotation and shear displacement is shown in Figure 22; it can be seen that the rotation of each joint has a negative correlation with the change of compaction degree, and the influence was more obvious to the J3 joint that produced the largest rotation. The change of compaction degree also had a negative correlation on the shear displacement of each joint to a certain extent. The denser the sand cushion layer was, the smaller the shear displacement of the joint was. It is worth noting that the change of compaction degree did not influence the location of the maximum rotation and maximum shear displacement. From the results, it can be seen that the change of compaction degree can affect the vertical deformation of joints, but the influence is very limited.

3.5. Influence of Buried Depth. In order to investigate the influence of buried depth on the mechanical response of the joint, in addition to the standard working condition of $1.0 \mathrm{~m}$, two burial depths were studied: $0.8 \mathrm{~m}$ and $1.2 \mathrm{~m}$. The circumferential maximum principal stress of the bell-andspigot is shown in Figure 23. From the figure, it can be seen that the maximum principal stress distribution rule of the joint was unchanged with the increase of the buried depth of

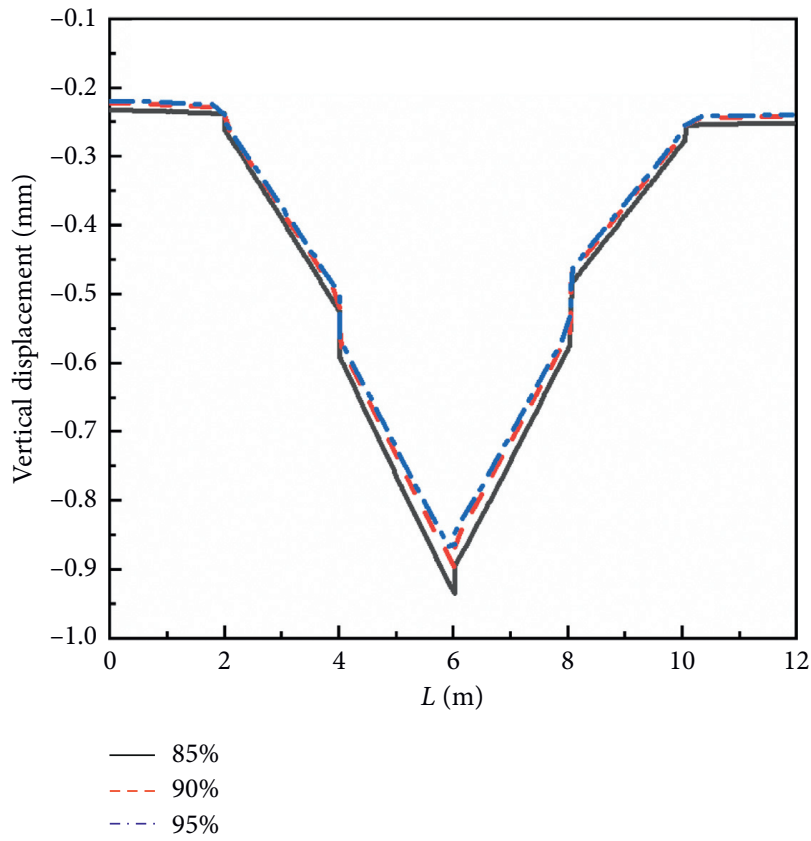

FIGURE 21: Longitudinal vertical displacement of the crown.

the pipeline, and there were still obvious peak and valley, which also increased to a certain extent with the increase of the buried depth. Among them, the maximum principal stress values at the crown and invert changed obviously, and the influence of the buried depth on the crown and invert of the bell was more obvious than the influence of the spigot, presumably due to the special shape of the joint.

When the load acted above the central pipe joint, the vertical displacement of the pipe crown under different 


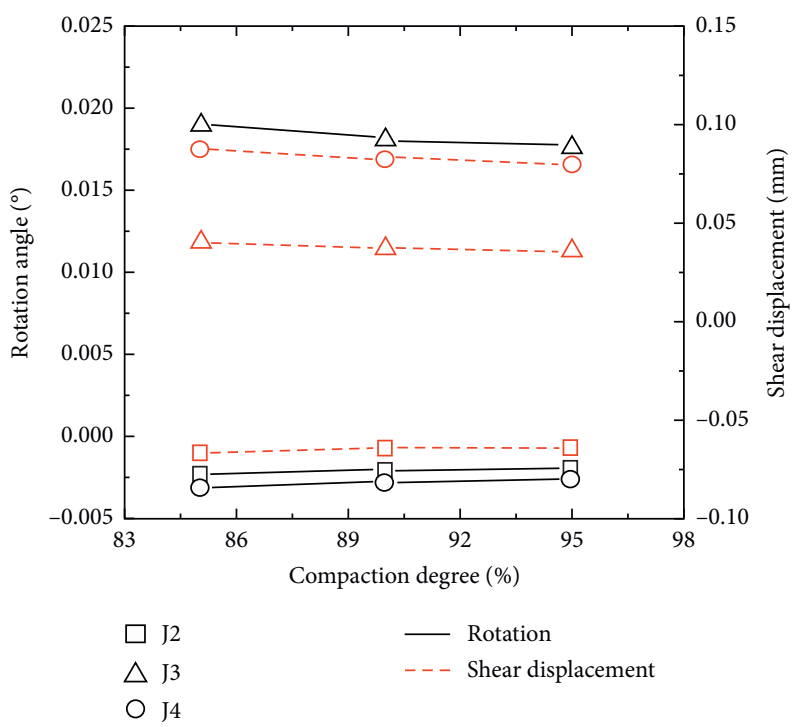

Figure 22: Influence of compaction degree on joint under different compaction degrees rotation and shear displacement.

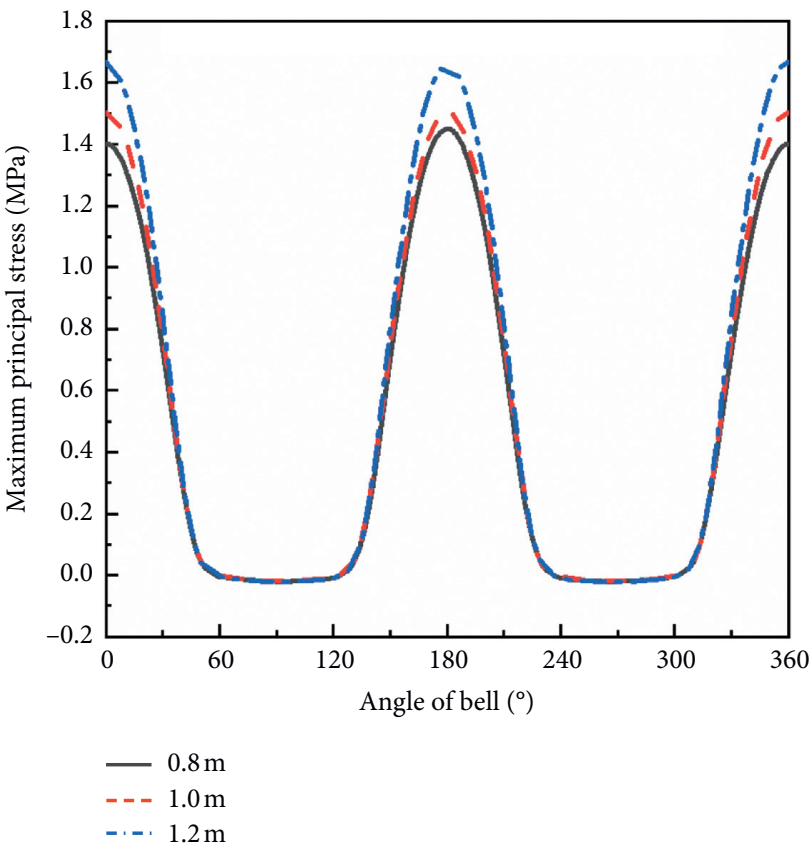

(a)

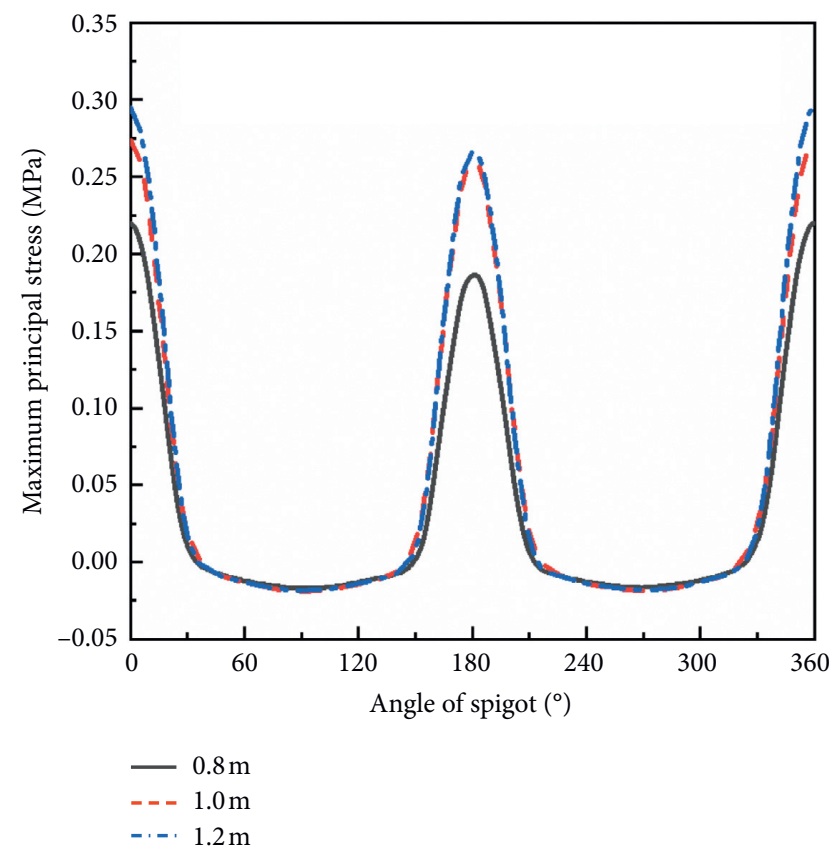

(b)

FIGURE 23: Maximum principal stress of (a) the bell and (b) the spigot under different burial depths.

buried depths is shown in Figure 24. It can be seen that the vertical displacement distribution rule was not affected with the increase of buried depth, but the displacement along the pipeline was reduced, and the displacement reduction of the central two pipes was the largest, which indicated that the influence of the variation of the buried depth on the vertical displacement of the pipeline was mainly concentrated at the central pipe joint. The distribution of the rotation and shear displacement of J2, J3, and J4 joints are calculated as shown in Figure 25, from which it can be found that the rotation of each joint obviously decreased with the increase of buried depth, but the maximum rotation still appeared at J3 joint, and the reduction of $\mathrm{J} 3$ joint rotation was obviously larger than that of the other two joints. The shear displacement of each joint was nonlinearly affected by the change of the burial depth. When the buried depth was from $0.8 \mathrm{~m}$ to $1.0 \mathrm{~m}$, the shear displacement of J4 and J2 joints increased, but the J3 joint decreased to a certain extent. When the depth was from $1.0 \mathrm{~m}$ to $1.2 \mathrm{~m}$, the shear displacement of J4 and J2 pipe joints showed a decreasing trend, but J3 joints had little change at this time. Especially when the burial depth was $0.8 \mathrm{~m}$, the maximum shear displacement occurred at the $\mathrm{J} 3$ 


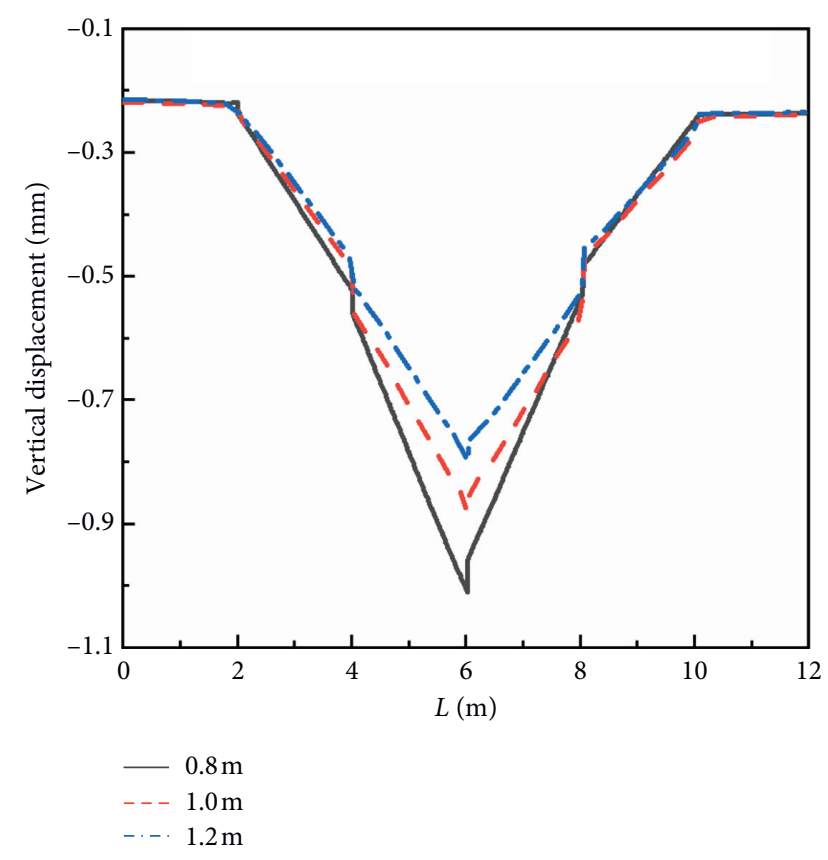

Figure 24: Longitudinal vertical displacement of the crown.

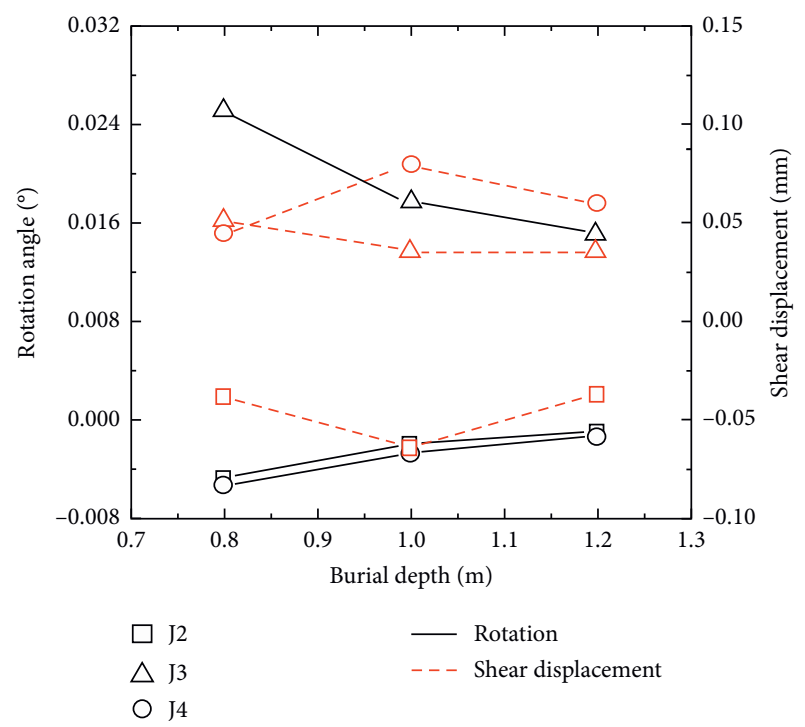

Figure 25: Influence of burial depth on joint rotation under different burial depths and shear displacement.

joint instead of the $\mathrm{J} 2$ joint. Based on the result, it can be found that the change of buried depth has a significant effect on the longitudinal behavior and circumferential stress of the pipe joint.

3.6. Influence of Load Position. Becerril García and Moore [7] found that when the load did not directly act above the central pipe joint, a larger shear displacement will occur, but in these studies, only a small number of load positions have been studied on the longitudinal behavior of the joint, and the results of $\mathrm{Xu}$ et al. [6] showed that when the load acted above the pipe segment, the maximum shear displacement will occur at the pipe joint. Therefore, in order to better analyze the influence of load position on the circumferential stress and vertical deformation of the joint under the fluidstructure coupling, twelve load positions are studied in this section, six of which acted above the front of the central pipe joint (offsets were $0.2 \mathrm{~m}, 0.4 \mathrm{~m}, 0.6 \mathrm{~m}, 0.8 \mathrm{~m}, 1.0 \mathrm{~m}$, and $1.2 \mathrm{~m}$ ), and the other six acted above the rear of the central pipe joint (offsets were $-0.2 \mathrm{~m},-0.4 \mathrm{~m},-0.6 \mathrm{~m},-0.8 \mathrm{~m}$, $-1.0 \mathrm{~m}$, and $-1.2 \mathrm{~m}$ ), as shown in Figure 26, and the traffic load adopted the standard amplitude of $0.7 \mathrm{MPa}$.

The circumferential maximum principal stress of the joint under different load positions is shown in Figure 27, from which it can be seen that the change of the load position had a significant influence on the circumferential stress of the bell and spigot, with the influence range concentrated at the crown and invert. Through comparison, it can be found that when the load acted above the central pipe joint, the invert of the joint had the peak maximum principal stress, and the stress decreased with the increase of the load position offset; when the load position was offset towards segment P4 (offset $>0$ ), the invert of the bell had the larger stress than that towards the other side, while the maximum principal stress of the invert of the spigot also had an opposite rule. The maximum principal stress of the crown of the spigot-and-bell joint was nonlinearly affected by the change of the load position. When the load position moved from $-1.2 \mathrm{~m}$ to $1.2 \mathrm{~m}$, it can be seen that the maximum principal stress of the bell crown firstly increased, reached a peak value at $0.6 \mathrm{~m}$, and then gradually decreased. However, when the load position moved from $1.2 \mathrm{~m}$ to $-1.2 \mathrm{~m}$, the maximum principal stress of the spigot crown also had a similar rule.

The vertical displacement at the crown of the pipeline under different load positions are shown in Figures 28(a) and 28(b), from which it can be seen that load position had a significant impact on the vertical deformation of the pipeline, and when the offset exceeded $1.0 \mathrm{~m}$, the generation of the maximum displacement of the crown was no longer at the central joint but at the adjacent joint under offset action. Figure 29 summarizes the movement of the rotation and shear displacement of $\mathrm{J} 2, \mathrm{~J} 3$, and $\mathrm{J} 4$ joints. It can be found that the maximum rotation of the joint occurred at J3 when the load acted above the central joint. As the load position moved backward (offset $<0$ ), the rotation of $\mathrm{J} 2$ showed an increasing trend, and the rotation of the $\mathrm{J} 3$ and $\mathrm{J} 4$ decreased to different degrees, respectively, with J3 decreasing more. When the load offset position exceeded $-0.8 \mathrm{~m}$, the maximum rotation of the joint appeared at J2. As the load position moved forward (offset $>0$ ), the rotation of $\mathrm{J} 4$ showed an increasing trend, and the maximum rotation of the joint appears at $\mathrm{J} 4$ after offset of $1.0 \mathrm{~m}$. The difference in offset between the two positions is caused by the asymmetry of the joint structure, and the shape of the bell caused it to suffer more resistance from the surrounding soil than the spigot, so it is more difficult to rotate. As can be seen from Figure 29, when the load acted above the J3 joint, the maximum shear displacement of the joint appeared at the J4 joint. When the load position moved backward, the shear displacement of 


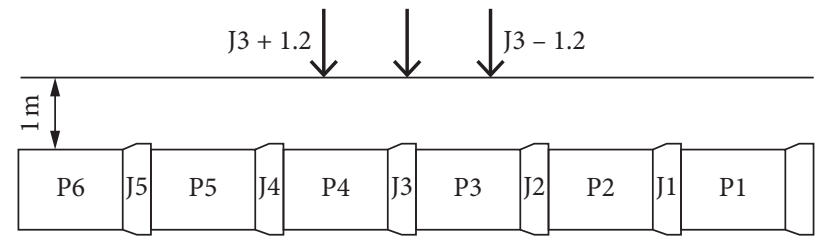

Figure 26: Definition of the load position.
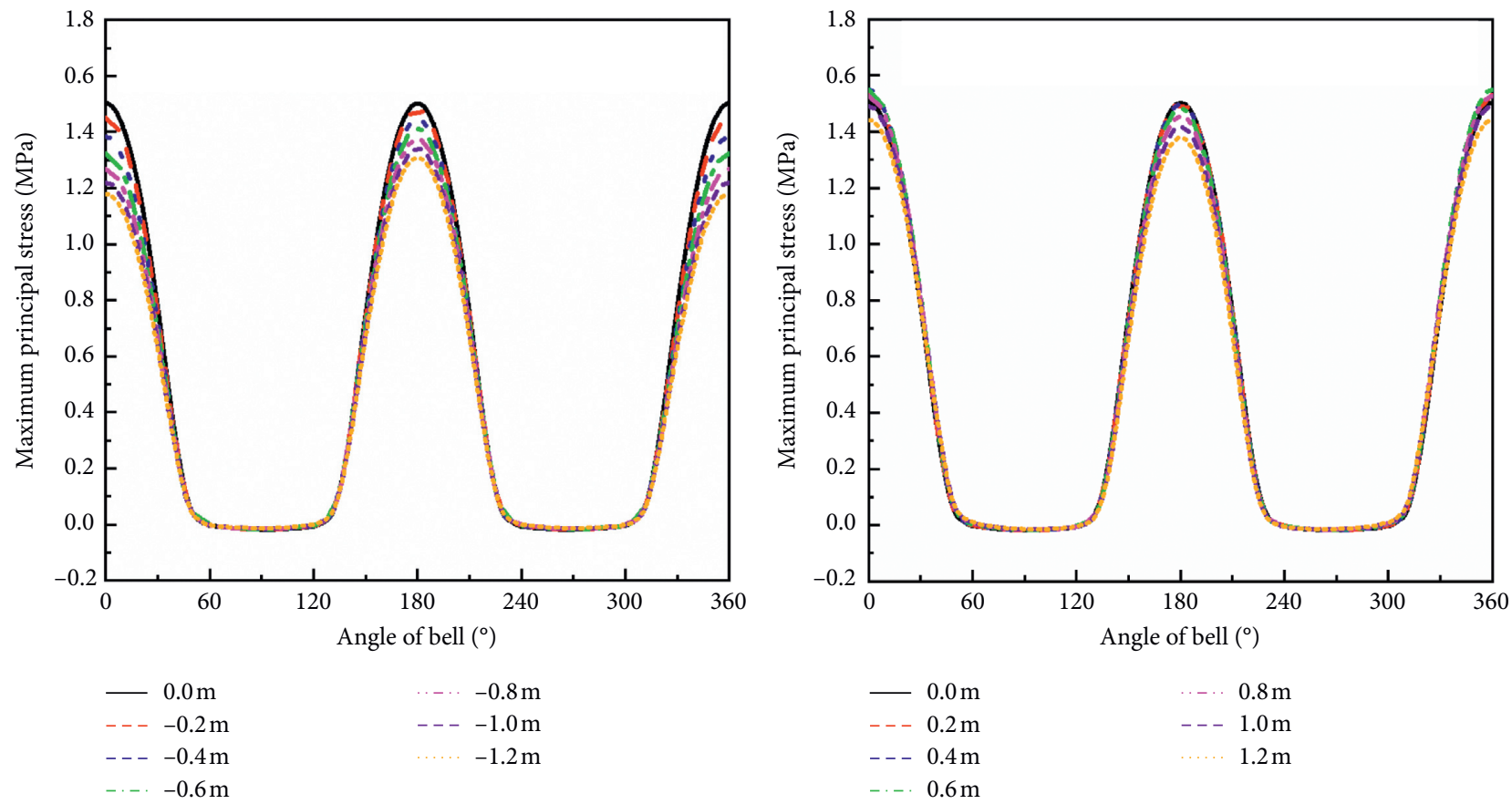

(a)
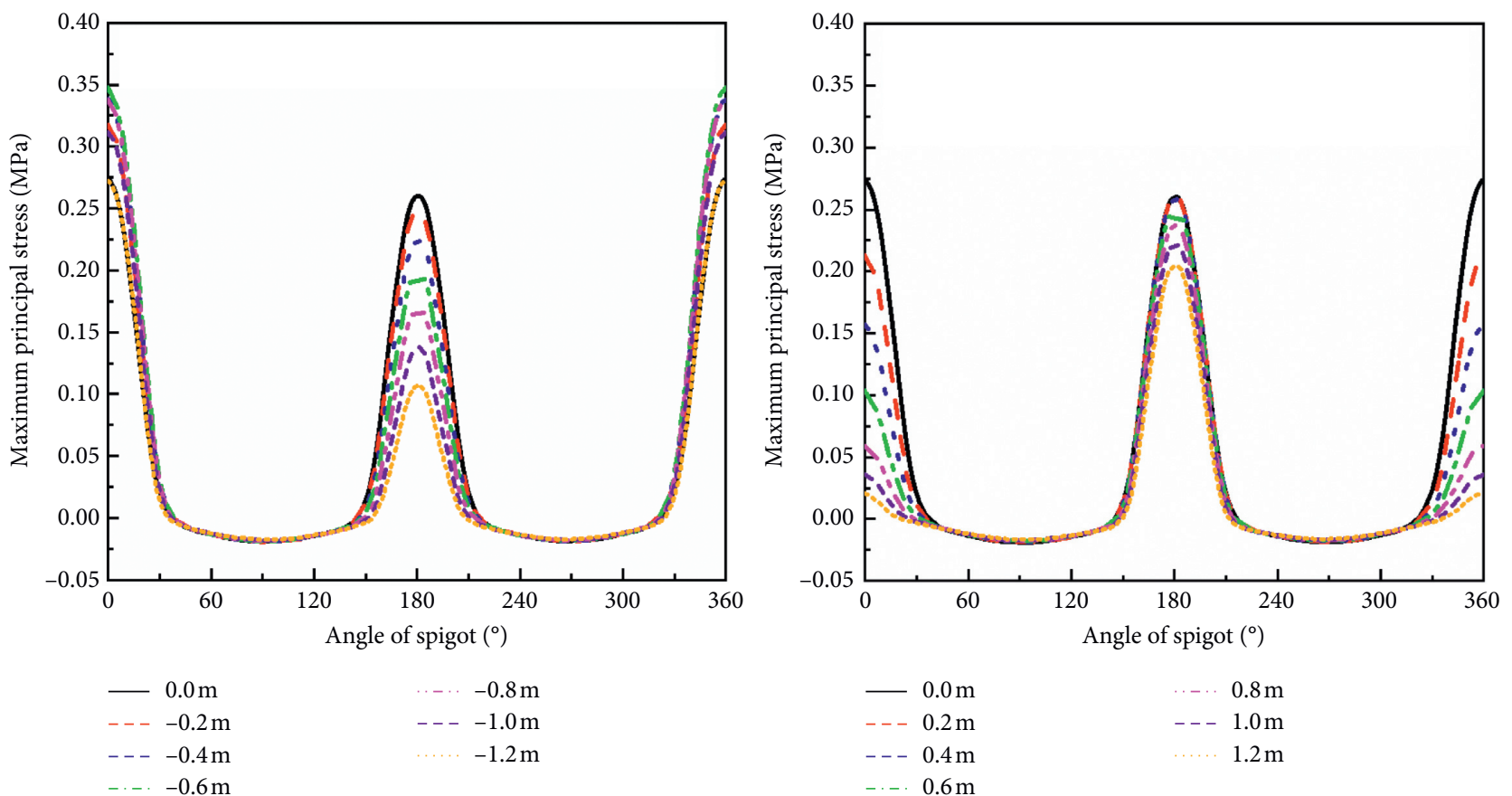

(b)

FIgURE 27: Maximum principal stress of (a) the bell and (b) the spigot with different load positions. 


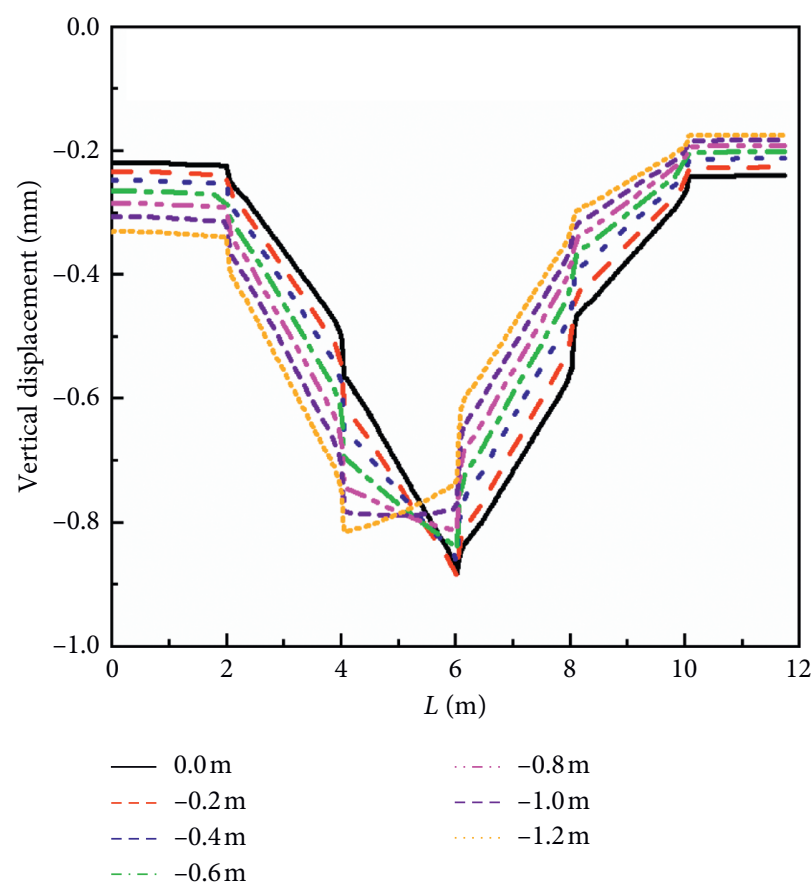

(a)

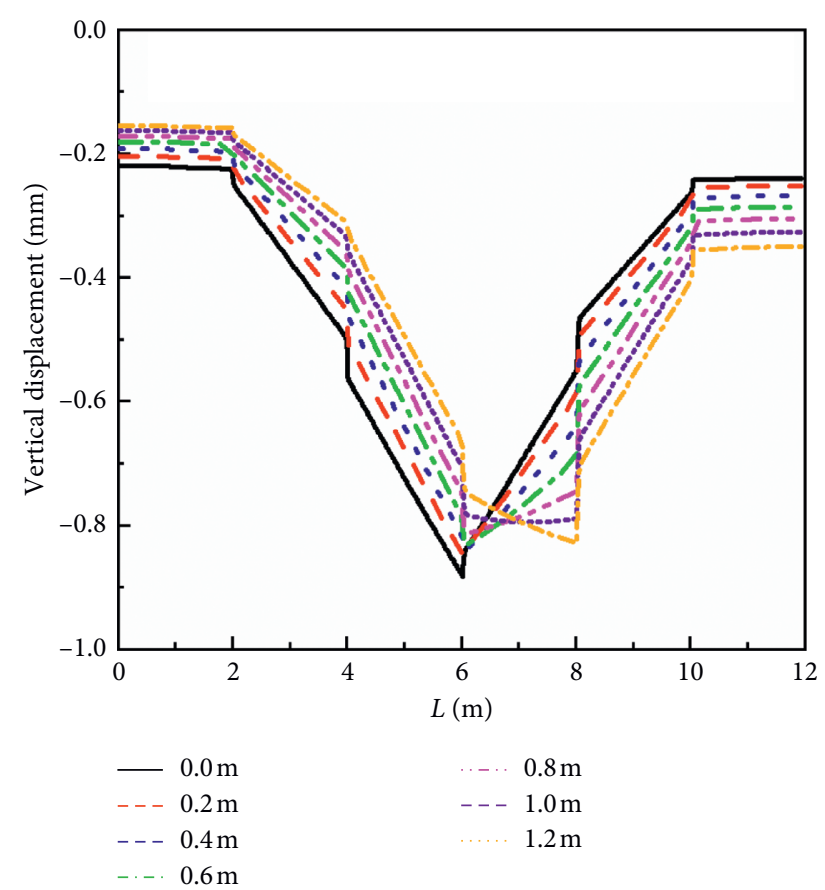

(b)

Figure 28: Longitudinal vertical displacement of the crown with different load positions: (a) above spigot and (b) above bell.

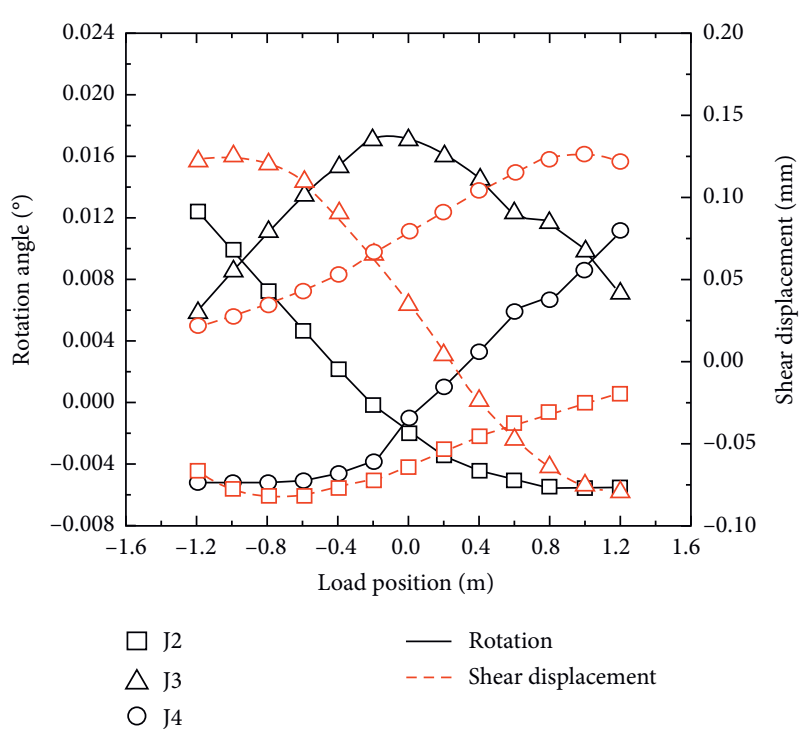

FIGURE 29: Influence of load position on joint rotation and shear displacement.

the J3 joint firstly increased and reached a peak when the offset was $-1.0 \mathrm{~m}$, then decreased, the shear displacement of J2 pipe joint also increased first and then decreased, but reached the peak value when the offset was $-0.8 \mathrm{~m}$. However, the shear displacement of the J4 joint always showed a decreasing trend. When the offset exceeded $-0.2 \mathrm{~m}$, the shear displacement of the J3 joint was larger than that of the J4 joint. When the load position moved forward, the shear displacement of the $\mathrm{J} 3$ joint decreased first and increased continuously after negative value occurred when the offset exceeded $0.2 \mathrm{~m}$. The shear displacement of the $\mathrm{J} 2$ joint showed a decreasing trend, while the shear displacement of the J4 joint increased first, reached a peak value at the offset of $1.0 \mathrm{~m}$, and then showed a decreasing trend. From the above comparison, it can be found that the change of load position will influence the position where the maximum rotation and shear displacement occurred, and the influence on the mechanical response of each joint will be more obvious.

\section{Comparison between Test Results and Simulation Results}

A full-scale test of a concrete pipe with a diameter of $1.0 \mathrm{~m}$ under multiple field loads was carried out in the National Major Infrastructure Testing and Restoration Technology Local Joint Engineering Laboratory, the pipeline consisted of six sections of concrete pipes with gasketed bell-and-spigot joints, the working length of each section of pipe is $2.0 \mathrm{~m}$, and the buried depth of pipeline is $1.0 \mathrm{~m}$, the bottom of the pipeline was provided with sand and gravel cushion according to relevant specifications. Rectangular inspection wells with a length of $2.6 \mathrm{~m}$ and a height of $3.0 \mathrm{~m}$ were set up on both sides of the pipeline to facilitate the entry of the fixed pipeline into the construction and facilitate water passing through the pipe to apply fluid load. The schematic diagram of the full-scale test is shown in Figure 30.

In the test, the material of the pipeline was also C30 concrete, and the size of the pipeline was basically consistent with the numerical model. The pipeline cushion was divided into two base layers of gravel and gravel, the compactness and gradation met the requirements of relevant 

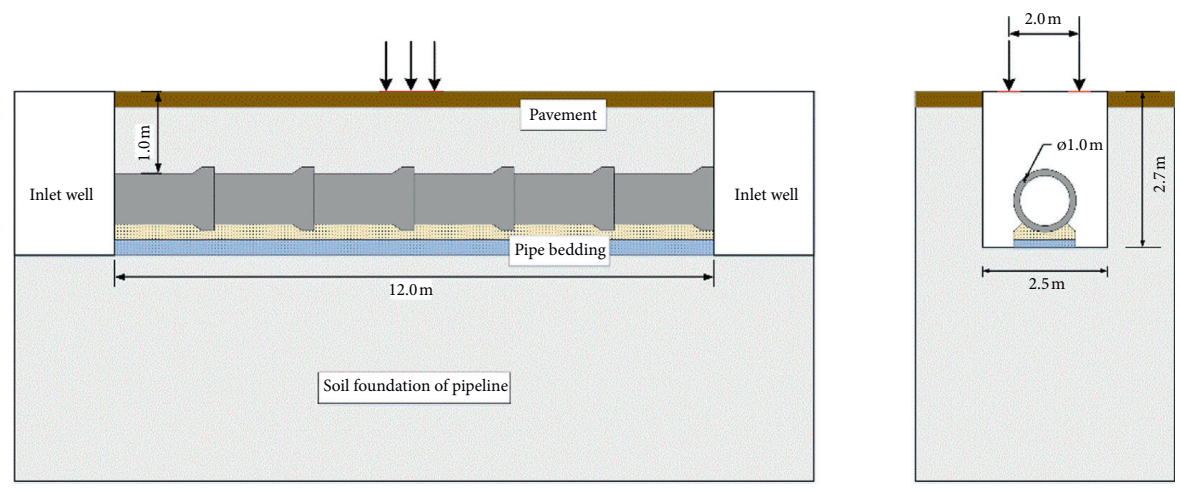

FIGURE 30: Full-scale test of multiphysics coupling of the concrete pipeline.

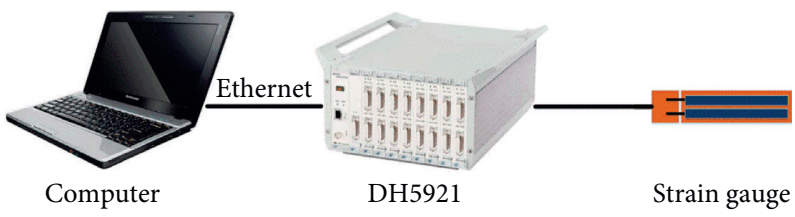

FiguRE 31: DH5921 dynamic strain testing system.

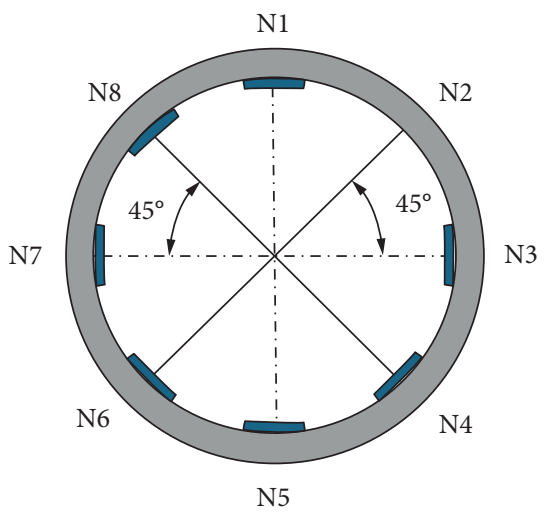

Spigot

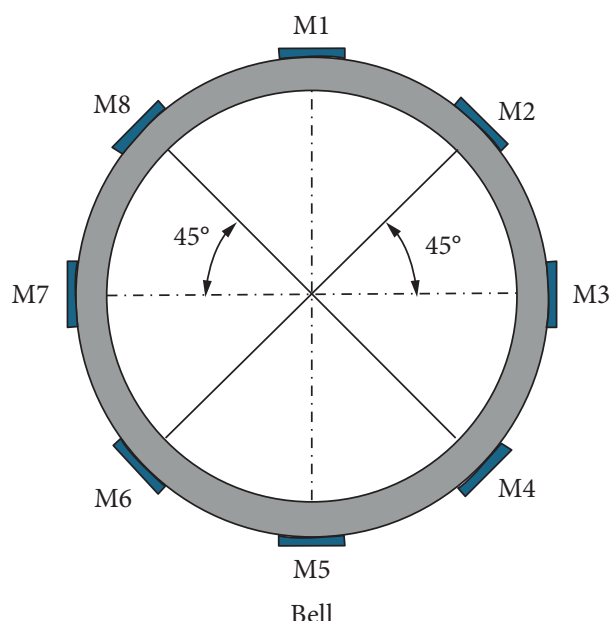

Bell

FIgURE 32: Circumferential sticking position of strain gauge.

specifications, and the backfill soil was compacted with a compactor. The data acquisition instrument adopted the DH5921 dynamic tester, as shown in Figure 31, and the sampling frequency in this test was $10 \mathrm{~Hz}$. The circumferential resistance strain gauges (model BQ120-80AA-P200) were pasted on the inner wall surfaces of the central bell and spigot to collect circumferential strains of various parts; the position of the strain gauges is shown in Figure 32. A water pump was used to apply a fluid load to the interior of the pipeline through the inspection well. A heavy truck with a standard block drove at a certain speed above the pipeline to apply a load to the central pipe joint.

Because there are many simulated working conditions, it is difficult to verify all of them, so the simulation results and test results under standard working conditions (the flow rate is $2 \mathrm{~m} / \mathrm{s}$, the flow is 0.5 , the hardness of the gasket is THA55, the buried depth is $1.0 \mathrm{~m}$, the compactness of sand cushion is $95 \%$, and the magnitude of traffic load is $0.7 \mathrm{MPa}$, which acted directly above the central pipe joint) are used as the comparison. As the strain data was finally collected during the test, the circumferential strain data of the J3 bell and the spigot under the load location are compared in this section, and the results are summarized as shown in Figure 33.

Figure 33 shows the circumferential strain distribution inside the bell and spigot under the effects of test and simulation. It is clear that the numerical simulation results show reasonable consistency with the distribution trend of the test results, verifying the accuracy of the model. Moreover, the strain distribution in Figure 33 was basically consistent with the distribution in the literature [14]. Therefore, it can be considered that the numerical simulation method adopted in this multifield fluid-structure 


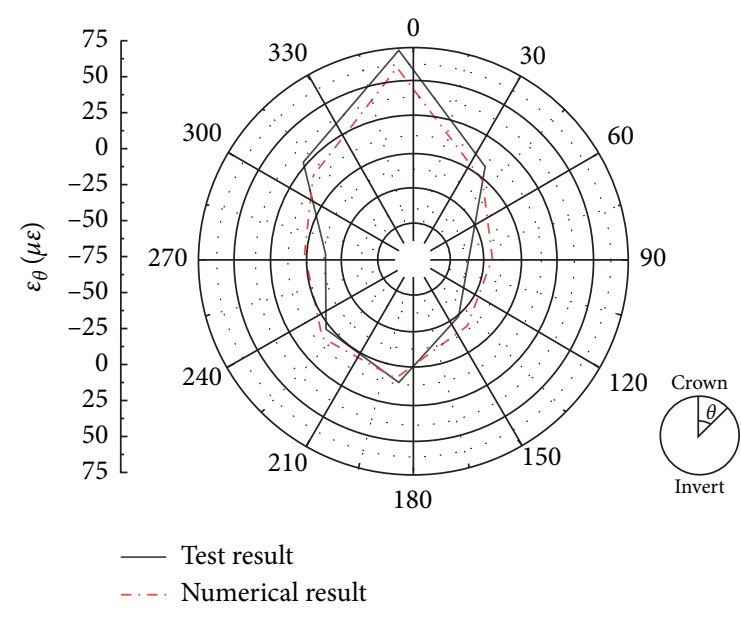

(a)

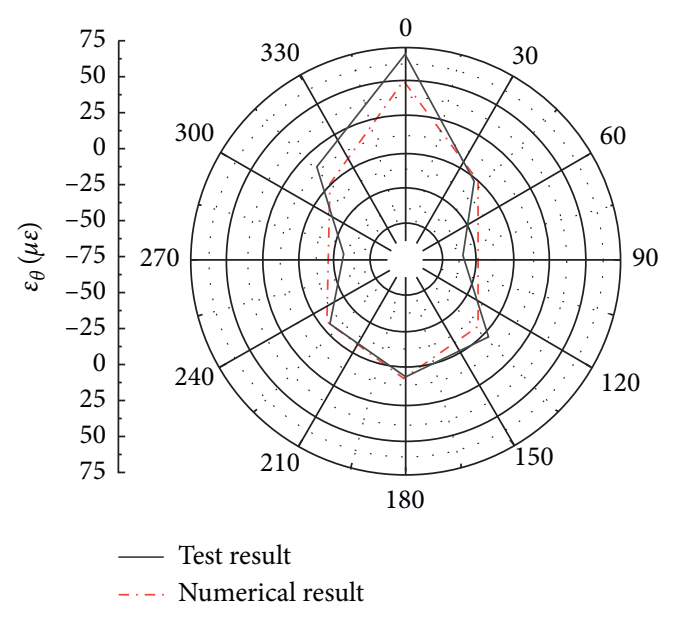

(b)

Figure 33: Comparison of the experimental and simulated circumferential strain of (a) central bell and (b) central spigot.

coupling is feasible. In addition, it can also be found from Figure 33 that the circumferential strain distribution of the bell and spigot collected is approximately the same. The circumferential strain at the crown and invert is relatively large, which is a tensile area. And because of the compressive and tensile properties of concrete, the crown and invert are also areas that are easily damaged, and the maximum strain occurs at the crown. While the range of the shoulder and the hip is a compression area, and the strain value is relatively small.

\section{Conclusion}

The purpose of this paper is to study the mechanical response of the joints of a concrete pipeline during operation, so a three-dimensional model of $1000 \mathrm{~mm}$ inner diameter concrete buried pipeline with gasketed bell-and-spigot joints and the flow field model inside the pipe was established. Fully considering the influence of pipeline assembly on the joint, the fluid-structure coupling numerical simulation was carried out with the help of the MpCCI platform under considering the influence of the gasket compression on the joint during the pipeline assembly process, the following conclusions are obtained.

(1) Through comparison with the full-scale test of the pipeline that has been carried out, it was found that the distribution trend of the numerical simulation results and the test results showed a reasonable consistency, which verified the rationality of the numerical model.

(2) The influence of different working conditions on the distribution of the maximum circumferential principal stress of the joint is mainly concentrated on the crown and invert of the joint, which are also the most vulnerable areas to tensile failure. Among them, the buried depth and the loading position have the most obvious effect; the difference caused by the changes of gasket hardness and cushion compaction degree is smaller on the contrary, while the influence of flow velocity and flow on the circumferential stress of the spigot is more obvious than that of the bell.

(3) The change of fluid force (flow velocity and flow) has a positive correlation with the vertical displacement of the pipe but has little effect on the vertical deformation of the joint. The vertical deformation of the joint is affected linearly to some extent by the change of gasket hardness and cushion compaction degree. The increase of burial depth has a significant negative correlation on the rotation distribution of joints, while the influence of shear displacement is nonlinear. The movement of the load position significantly affects the vertical deformation distribution of the joints and presents obvious nonlinearity.

(4) The conclusion based on sensitivity analysis of various factors provides a theoretical basis for further studying the mechanics of the joints of a concrete pipeline during operation.

\section{Data Availability}

The results data used to support the findings of this study are included within the supplementary information file.

\section{Conflicts of Interest}

The authors declare that there are no conflicts of interest regarding the publication of this paper.

\section{Acknowledgments}

This research was supported by the National Key Research and Development Program of China (no. 2016YFC0802400), the National Natural Science Foundation of China (no. 51978630, 51678536), the Program for Science and Technology Innovation Talents in Universities of Henan Province (Grant no. 19HASTIT043), and the Outstanding 
Young Talent Research Fund of Zhengzhou University (no. 1621323001).

\section{References}

[1] A. E. Romer and K. K. Kienow, "Rubber gasket concrete pipe joints eliminating the smoke and mirrors," in Proceedings of the ASCE Pipeline Engineering and Construction, pp. 1-13, San Diego, CA, USA, July 2004.

[2] S. M. Elachachi, D. Breysse, and L. Houy, "Longitudinal variability of soils and structural response of sewer networks," Computers and Geotechnics, vol. 31, no. 8, pp. 625-641, 2004.

[3] A. Benmansour, A. Abdallah, F. Masrouri, and G. Auvinet, "Analyse fiabiliste du comportement axial des conduites d'assainissement," Canadian Geotechnical Journal, vol. 34, no. 3, pp. 329-343, 1997.

[4] J. H. Scarino, "Buried pipelines: providing flexibility at structures," Transportation Engineering Journal of ASCE, vol. 108, no. 3, pp. 267-281, 1982.

[5] B. Rakitin and M. Xu, "Centrifuge modeling of large-diameter underground pipes subjected to heavy traffic loads," Canadian Geotechnical Journal, vol. 51, no. 4, pp. 353-368, 2014.

[6] M. Xu, D. Shen, and B. Rakitin, "The longitudinal response of buried large-diameter reinforced concrete pipeline with gasketed bell-and-spigot joints subjected to traffic loading," Tunnelling and Underground Space Technology, vol. 64, pp. 117-132, 2017.

[7] D. Becerril García and I. D. Moore, "Behaviour of bell and spigot joints in buried reinforced concrete pipelines," $\mathrm{Ca}$ nadian Geotechnical Journal, vol. 52, no. 5, pp. 609-625, 2015.

[8] J. Buco, F. Emeriault, and R. Kastner, "Full-scale experimental determination of concrete pipe joint behavior and its modeling," Journal of Infrastructure Systems, vol. 14, no. 3, pp. 230-240, 2008.

[9] F. Wang, H. Fang, B. Li, and C. Chen, "Dynamic response analysis of drainage pipes with gasketed bell and spigot joints subjected to traffic loads," Chinese Journal of Geotechnical Engineering, vol. 40, no. 12, pp. 2274-2280, 2018.

[10] B. Li, H. Fang, K. Yang, P. Tan, and F. Wang, "Dynamic analysis of concrete pipes under the coupled effects of traffic load and groundwater level fluctuations," Energy Science \& Engineering, vol. 8, no. 1, pp. 203-215, 2020.

[11] K. Zhai, H. Fang, B. Fu, F. Wang, and B. Hu, "Mechanical response of externally bonded CFRP on repair of PCCPs with broken wires under internal water pressure," Construction and Building Materials, vol. 239, Article ID 117878, 2020.

[12] B. E. Laithier and M. P. Païdoussis, "The equations of motion of initially stressed Timoshenko tubular beams conveying fluid," Journal of Sound and Vibration, vol. 79, no. 2, pp. 175-195, 1981.

[13] D. C. Wiggert and A. S. Tijsseling, "Fluid transients and fluidstructure interaction in flexible liquid-filled piping," Applied Mechanics Reviews, vol. 54, no. 5, pp. 455-481, 2001.

[14] B. Li, H. Fang, H. He, K. Yang, C. Chen, and F. Wang, "Numerical simulation and full-scale test on dynamic response of corroded concrete pipelines under multifield coupling," Construction and Building Materials, vol. 200, pp. 368-386, 2019.

[15] Q. Xu, J. Feng, and S. Zhang, "Effects of different loads on structure stress of "L"-type large-diameter buried pipe network based on fluid-structure-heat coupling," International Communications in Heat and Mass Transfer, vol. 86, pp. 222-230, 2017.
[16] Z. Zhang and X. Li, "Comparative analysis of tee pipe coupling fluid-solid, fluid-solid thermal coupling calculation," Journal of Gansu Sciences, vol. 28, no. 5, pp. 79-83, 2016.

[17] B. Li, H. Fang, K. Yang, and F. Wang, "Dynamic analysis of concrete pipes under the coupled effects of traffic load and groundwater level fluctuations," Energy Science \& Engineering, vol. 8, no. 1, pp. 203-215, 2019.

[18] B. Li, H. Fang, K. Yang, H. He, P. Tan, and F. Wang, "Mechanical response and parametric sensitivity analyses of a drainage pipe under multiphysical coupling conditions," Complexity, vol. 2019, Article ID 3635621, 24 pages, 2019.

[19] China Institute of Building Standard and Research, Municipal Drainage Pipeline Process and Ancillary Facilities (06MS201), China Planning Press, Beijing China, 2007.

[20] J. Lee and G. L. Fenves, "Plastic-damage model for cyclic loading of concrete structures," Journal of Engineering Mechanics, vol. 124, no. 8, pp. 892-900, 1998.

[21] S. Zhang, Experimental Research and Numerical Simulation of the Mechanical Properties of the Pipe Rubber Seals, Henan University of Technology, Zhengzhou, China, 2013.

[22] C. Liu, C. M. Cady, M. L. Lovato, and E. B. Orler, "Uniaxial tension of thin rubber liner sheets and hyperelastic model investigation," Journal of Materials Science, vol. 50, no. 3, pp. 1401-1411, 2015.

[23] B. Zhang, H. Fang, Y. Zhong, and F. Wang, "Application of GPR and FWD in comprehensive evaluation of the performance of old roads," Journal of China \& Foreign Highway, vol. 2008, no. 5, pp. 89-93, 2008.

[24] T. Zhang, Z. Yin, and G. Mao, "Numerical simulation of turbulence in curved circular duct," Journal of Hydroelectric Engineering, vol. 24, no. 3, pp. 61-65, 2005.

[25] D. Zheng, M. He, and D. Che, "CFD simulations of hydrodynamic characteristics in a gas-liquid vertical upward slug flow," International Journal of Heat and Mass Transfer, vol. 50, no. 21-22, pp. 4151-4165, 2007.

[26] Ministry of Housing and Urban-Rural Development and General Administration of Supervision, Inspection and Quarantine of the People's Republic of China, Code for Design of Outdoor Wastewater Engineering (GB50014-2006), China Planning Press, Beijing China, 2011. 